\title{
Colorectal Cancer in Ulcerative Colitis Patients
}

\author{
Joseph D. Feuerstein and Sharmeel K. Wasan \\ Boston University School of Medicine \\ USA
}

\section{Introduction}

The association between ulcerative colitis (UC) and colorectal cancer (CRC) was first reported in the 1920s (Crohn \& Rosenberg, 1925). Since then, numerous studies have confirmed the overall risk of developing colorectal cancer associated with UC, and inflammatory bowel disease (IBD) in general. Many studies incorporate both UC and Crohn's colitis together with regards to their risk of colorectal cancer. While more recent studies have questioned how substantial the increased risk of colorectal cancer truly is in UC, relative to the general population, specific characteristics of UC patients increase their overall risk of developing CRC. In fact, CRC is one of the most serious complications of IBD and accounts for approximately $10-15 \%$ of the deaths in IBD patients (Munkholm et al, 2003). To reduce this complication, UC related CRC screening programs should focus on the individuals' risk of developing CRC with the goal of early identification of the cancer and subsequent increased overall survival.

\section{Risk factors for developing colorectal cancer}

Patients with UC are at an overall increased risk of developing CRC compared to the general population. This risk is additive to the baseline risk of developing sporadic CRC. The average age at diagnosis of UC related CRC ranges from 43.2 to 50.9 years (Eaden et al., 2001a; Lakatos \& Lakatos, 2006). In addition to age, significant risk factors include the extent of colonic disease, age of onset and duration of disease, degree of inflammation, and the presence of primary sclerosing cholangitis. All these factors are crucial to prognosticate the patients overall risk and discuss treatment options.

\subsection{Overall risk}

While the risk of developing CRC in patients with UC is increased, the magnitude is challenging to estimate. Multiple studies with differing methodologies (population based cohorts versus populations from tertiary referral centers) have been performed and have reported varying risk estimates for the development of CRC. This difference may in part be due to the fact that some tertiary care centers opt for earlier colectomy or early therapy with aminosalicylates which may reduce the reported incidence of CRC. In 2001 a meta-analysis by Eaden and Abrams found the cumulative incidence of CRC in UC patients to be $2 \%$ at 10 years of disease, $8 \%$ after twenty years, and $18 \%$ after thirty years of disease. However, even this meta-analysis may overestimate the risk of CRC given the large percentage of patients who were treated only in tertiary care centers. Data from the Olmsted County database in 
the United States (US) did not find any increased risk of CRC in UC over a fourteen year follow up (Jess et al., 2006). A more recent study in the Netherlands looking at 26,855 patients with IBD (both ulcerative colitis and Crohn's disease) under the age of 65 found an overall incidence of $0.04 \%$ colitis related CRC (Baars et al., 2011). Despite these varying estimates, it appears that there is an increased risk of developing CRC, although the exact number is difficult to approximate.

\subsection{Anatomic extent of disease}

Anatomic extent of disease has been reported as one of the most important predictors of CRC risk in UC. Extent of disease is defined by the most extensivedisease noted histologically or endoscopically at any time (Mathy et al., 2003). Extent of disease is usually classified as pancolitis, left sided colitis, proctosigmoiditis, or proctitis. The definition of left sided colitis, unfortunately, varies in the literature; while most studies report it to be up to the splenic flexure, other studies extend it to the hepatic flexure. Overall, subtotal or pancolitis carried a relativerisk of 14.8 to 19.2, while for left sided disease, the relative risk was 2.8. (Ekbom et al., 1990; Gyde et al., 1988). Isolated proctosigmoiditis or proctitis did not significantly increase the risk of CRC (Jess et al., 2006; Langholz et al., 1992). In more recent studies, presence of backwash ileitis also did not increase the risk of CRC. (Haskell et al., 2005). The increased risk related to extent of disease is most significant in pancolitis patients during the first two decades of disease. By the fourth decade of disease, however, the incidence of CRC among pancolitis and L sided colitis equalizes (Greenstein et al., 1979; Gyde et al., 1988). Thus, these two groups of UC patients are recommended to undergo surveillance colonoscopy with biopsies given their increased risk.

\subsection{Age of onset and duration of disease}

The younger the age of onset of ulcerative colitis, the higher the patient's risk of cancer. After 35 years of follow-up, patients with extensive colitis diagnosed before the age of 15 had a cumulative risk of CRC of $40 \%$. Patients diagnosed with UC between the ages of 15-39 had a lower, but still substantial, cumulative risk of CRC of 25\% (Ekbom et al., 2006). However, this increased risk has not been substantiated in all studies. Greenstein et al estimated that patients aged 10-19 at diagnosis of left sided or pancolitis had an incidence of CRC of 3.6 per 1000 patient years. This incidence was increased to 12.7 per 1000 patient years in patients diagnosed between ages 30-39 (Greenstein et al., 1979). A recent study found a small but statistically significant increased risk of CRC with duration of disease (Baars et al., 2011). However CRC is rarely found when disease duration is less than eight to ten years (Ransohoff, 1988). Even in patients with extensive colitis, no cancers were detected during the first decade of follow up in 1406 patient-years (Lennard-Jones et al., 1990). In cases where CRC was diagnosed, the mean duration of disease from time of diagnosis of UC was seventeen years (Pinczowski et al., 1994). Considerations therefore for CRC screening due to UC are based on disease duration, not patient age. It is important to remember that in addition to UC related risks of CRC, UC patients also develop the same increased risk of age-related sporadic CRC.

\subsection{Degree of inflammation}

The severity of inflammation noted on colonoscopy is also associated with CRC. A study by Rutter et al reviewed patients with UC and CRC or dysplasia compared to UC patients 
without CRC or dysplasia. Inflammation was categorized as chronic/quiescent, mild, moderate, or severe by colonoscopic and histologic means. In univarate analysis both colonoscopic and histologic signs of inflammation increased the risk of CRC (odds ratio 2.5 and 5.1 respectively) (Rutter et al., 2004d). The increased risk was more dramatic from histologic scoring (Gupta et al., 2007; Rutter et al., 2004d). A similar study confirmed these results noting the progression from histologic inflammation to dysplasia or CRC (Rubin et al., 2006a). The risk of developing CRC is still present even after areas of severe mucosal inflammation return to normal.

\subsection{Risks among males and females}

Initial studies found no difference in the risk of developing CRC between men and women. (Ekbom et al., 1990). However, a more recent study of 7,607 patients of whom 4,125 had UC, noted an overall lower risk of CRC amongst women compared to men. Relative to the general population women with UC still had an overall increased risk of CRC. However, compared to their male counterparts, women diagnosed before the age of forty five and with more than ten years of disease had a lower relative risk of CRC (Soderlund et al., 2010).

\subsection{Family history}

Just like the two to three fold increased risk of CRC in first degree relative of patients in the general population, having a family history of CRC further increases the UC patient's risk of cancer (Askling et al., 2001; Nuako et al., 1998a). This risk was even more substantial when the first degree relative developed CRC prior to the age of fifty (Askling et al., 2001).

\subsection{Associated Primary sclerosing cholangitis (PSC)}

A small subset of patients with UC (2-5\%) who develop PSC are at an even greater increased risk of developing CRC. This risk also increases with duration of disease. The risk of carcinoma or dysplasia in these patients was found to be $9 \%$ at ten years, $31 \%$ at twenty years, and 50\% after twenty five years of disease duration (Broome et al., 1995). While some studies have failed to replicate this finding (Loftus et al., 1996; Nuako et al., 1998b), a meta analysis of studies including patients with UC and PSC found a four fold increased risk of CRC (Soetikno et al., 2002). This risk of CRC was also noted even after orthotopic liver transplant for PSC with an approximate incidence of $1 \%$ per person year (Loftus et al., 1998). A study from the United Kingdom noted a much higher cumulative risk post transplantation with risks of $14 \%$ at five years and $17 \%$ at ten years post-transplantation (Vera et al., 2003). Given the dramatic increase risk of CRC associated with associated PSC, patients having both UC and PSC should initiate annual colonoscopy surveillance at time of PSC diagnosis.

\subsection{Miscellaneous risk factors}

Additional risk factors that are only noted on colonoscopy include strictures, shortened colon, and pseudopolyps. In a small retrospective study, true strictures were found in 15 of 469 patients with UC. Of these fifteen patients, there were twenty seven strictures noted. Two were cancerous at diagnosis and twenty three showed low or high grade dysplasia. Ultimately, thirteen of the fifteen patients underwent colectomy, and an additional four 
patients were found to have CRC (Lashner et al., 1990). Another retrospective study of hospitalized patients with UC found the prevalence of strictures to be $5 \%$, with $24 \%$ of the strictures being malignant. In all of these cases, the patients had more than twenty years of disease (Gumaste et al., 1992). Similarly, Rutter et al found that both strictures (odds ratio of 4.62 ) and post-inflammatory polyps (odds ratio of 2.29) conveyed a significantly increased risk of developing CRC (Rutter et al., 2004c). While post-inflammatory polyps do not develop directly into CRC, they are thought to act as a surrogate marker of previous severe inflammation which has been shown to carry significant risk of CRC (Rutter et al., 2004c). The risk of a malignant stricture increased with disease duration, location proximal to the splenic flexure, and presence of a symptomatic large bowel obstruction (Gumaste et al., 1992).

\begin{tabular}{|c|c|}
\hline Risk factors for UC related CRC & Relative Risk \\
\hline Anatomic extent of disease (pancolitis $>$ left sided) & +++ \\
\hline Duration of disease & +++ \\
\hline Co-morbid Primary sclerosing cholangitis & +++ \\
\hline Younger age of onset & ++ \\
\hline Inflammation & + \\
\hline Stricture & + \\
\hline Pseudopolyps & + \\
\hline Family history of colorectal cancer & + \\
\hline Male $>$ female & + \\
\hline Proctitis/Proctosigmoiditis & - \\
\hline Backwash ileitis & - \\
\hline Smoking & - \\
\hline
\end{tabular}

Table 1. Risk factors for colorectal cancer: + indicates increased risk and - indicates no proven increased risk

\section{Genetics of UC related CRC}

Similar to most cancers, genetic mutation, loss of function of tumor suppressor genes, oxidative stress, and errors in DNA mismatch repair all play critical roles in the development of UC associated CRC. Some of the genetic changes are similar to sporadic $\mathrm{CRC}$, but key aspects and timing of events differ. Many of these changes occur prior to any detectable mucosal changes. Unlike sporadic CRC which develops in a stepwise process over many years, UC associated CRC can progress rapidly without a classic slow progression.

\subsection{Genetics of UC associated CRC}

While chronic inflammation is a risk factor for developing cancer, in UC inflammation is only one aspect in the pathophysiology of CRC development. For example, despite the inflammation seen in proctitis and proctosigmoiditis, patients with this extent of disease do not convey an increased risk of cancer. The step-wise process in the development of CRC is similar to the well established "adenoma-carcinoma" sequence in sporadic CRC. Crypt foci 
or mircoadenoma, progress to large adenoma, to cariconma-in-situ, and then into invasive adenocarcinoma. The most common cause of sporadic CRC arises from chromosomal instability leading to abnormal segregation of chromosomes and aneuploidy. The chromosomal instability leads to loss of heterozygosity and eventually loss of function of tumor suppressor genes. The loss of function of the APC gene is a crucial initiating event in the development of most adenomas. In sporadic colorectal cancer, key underlying features include both chromosomal instability and microsatellite instability. Eventually there is the loss of the p53 tumor suppressor gene which is the transition from adenoma to carcinoma. The remaining $15 \%$ of sporadic CRC involve the microsatellite instability pathway involving the loss of function of DNA mismatch repair genes. Two of the genes commonly affected are hMLH1 and hMSH2. (Itzkowitz, 2003; Itzkowitz \& Yio, 2004)

Like sporadic CRC, UC related CRC develops from sequential steps of somatic genetic mutation and associated clonal expansion. While the same genetic mutations occur in UC related CRC, the timing and frequency is different. Approximately $80 \%$ of the cancers are related to chromosomal instability while $20 \%$ are related to microsatellite instability. In UC related CRC the main genetic alteration is in the allelic deletion of p53 in 50-85\% of cases (Itzkowitz \& Yio, 2004). In review of colectomy specimens, the p53 mutation preceded aneuploidy which in turn preceded p53 loss of heterzygosity (Brentnall et al., 1994). This loss of heterozygosity correlates with malignant progression, and is detected in $63 \%$ of low grade dysplasia and $85 \%$ of cases involving high grade dysplasia (Burmer et al., 1992). The p53 mutation was also detected at a high frequency $(>50 \%)$ in patients with UC and inflamed mucosa (Hussain et al., 2000). The APC mutation is extremely rare (0-3\%) and only occurs late in high grade dysplasia or cancer (Aust et al., 2002). Similarly, allelic deletion of the APC gene occurs in $<33 \%$ of colitis-related neoplasia (Umetani et al., 1999). Also different from sporadic CRC, the k-ras mutation is quite rare in UC related CRC, while BRAF mutation is more common (Lakatos \& Lakatos, 2008; Yashiro et al., 2001). Microsatellite instability occurs through the same process as in sporadic CRC, and involves mismatch repair defects of hMLH1, hMSH2, and hMSH6 (Lakatos \& Lakatos, 2008). In approximately $25 \%$ of cases, microsatellite instability was demonstrated two to twelve years before the diagnosis of CRC (Tahara et al., 2005).

\subsection{Oxidative stress}

The role of oxidative stress from chronic inflammation seems to play some role in the development of UC related CRC. Oxidative stress has multiple effects including cellular damage, contributing to the pathogenesis of colitis, and contributing to colon cancer carcinogenesis (Ullman \& Itzkowitz, 2011). The chronically inflamed tissue release reactive oxygen and nitrogen species (RONS) from cells in the innate immune system. Actively inflamed tissue in UC expresses increased levels of both RONS and nitric oxide synthase (Hussain et al., 2000; Itzkowitz \& Yio, 2004; Ullman \& Itzkowitz, 2011;). Furthermore, measurements of 8-hydroxydeoxyguanosine, a mutagen formed from hydroxal radicals is found to be increased in UC mucosa and even higher in specimens with dysplasia. . The formulation of free radicals affects metabolic processes that regulate DNA, RNA, proteins, and lipids. Once the genes or proteins affecting colonocyte homeostasis are affected, like p53, dysplasia and carcinoma ensue. Lastly, the oxidative stress has also been found to interfere with DNA mismatch repair enzymes, contributing to microsatellite instability as well (Ullman \& Itzkowitz, 2011). 


\subsection{DNA methylation}

DNA methylation also contributes to the development and progression of colitis-related CRC. The resulting methylation of $\mathrm{CpG}$ islands in several genes occurs prior to dysplasia and is found diffusely in the UC mucosa (Issa et al., 2001). The hMLH1 hypermethylation is noted in neoplastic mucosa most commonly with high levels of MSI (46\%) but is also found with low and no detected MSI (Fleisher et al., 2000; Ullman \& Itzkowitz, 2011). Hypermethylation of cell cycle inhibitor p16ink14a is frequently found in neoplastic specimens in colitis-related cancer (Hsieh et al., 1998). While $10 \%$ of samples without dysplasia already showed hypermethylation of the p16 promoter, the rates rapidly increased with degree of dysplasia reaching $100 \%$ in tumor samples (Ullman, 2011). Similarly, p14 ARF, which is an indirect regulator of p53, is encoded by the same gene as p16 ink14a. Loss of expression via hypermethylation is detected in $50 \%$ of adenocarcinoma specimens, $33 \%$ of dysplasic specimens, and $60 \%$ of mucosal samples with no dysplasia (Sato et al. 2002; Ullman \& Itzkowitz, 2011).

\begin{tabular}{|c|c|c|c|}
$\begin{array}{c}\text { Chromosomal } \\
\text { instability }\end{array}$ & $\begin{array}{c}\text { Microsatellite } \\
\text { instability }\end{array}$ & Hypermethylation & Oxidative stress \\
\hline Aneuploidy & hMLH1 & hMLH1 & Free radicals \\
P53 & hMSH2 & p16 ink14a & DNA mismatch repair enzymes \\
APC & hMSH6 & p14ARF & \\
$\begin{array}{c}\text { Chromosomal loss } \\
\text { of function }\end{array}$ & DPC4 & & \\
\hline
\end{tabular}

Table 2. Summary of genetic changes in colitis related colorectal cancer

\section{Pathophysiology of dysplastic lesions in ulcerative colitis}

Dysplasia is currently the best indicator of CRC risk in UC (Goldman, 1996). It is defined as neoplastic epithelium confined to the basement membrane that is categorized histologically by a mix of architectural and cytologic features (Guindi \& Riddell, 2001; Riddell et al., 1983). 75 to $90 \%$ of cancers in UC are noted to have underlying dysplasia with the classic progression from inflammation to dysplasia to carcinoma (Sharan \& Schoen, 2002). However, a substantial number of colitis associated cancers arise without any preceding dysplasia, but even these cancers only occur in areas of chronic or active inflammation (Goldman, 1996; Riddell et al., 1983; Woolrich et al., 1992). In studies looking at patients who underwent colectomy for CRC, dysplasia was absent in up to $25 \%$ of the specimens (Brackmann et al., 2009; Connell et al., 1994). Consequently, the absence of dysplasia alone does not rule out the possibility of carcinoma.

\subsection{Classification of dysplasia}

Biopsy specimens are classified based on microscopic morphology as (1) negative for dysplasia, (2) indefinite for dysplasia, or (3) positive for dysplasia (Ridell, 1983). While true dysplasia is classified based on the degree of cytologic and architectural atypia of the crypts and surface epithelium, distinguishing these features can be challenging. Indefinite for dysplasia classifies specimens that possess some cytologic and architectural features of low grade dysplasia but also has active inflammation or ulceration in the area making the 
neoplastic status unclear. The features include changes that are more extreme than expected in just regenerative changes, nuclear features that seem beyond those considered normal repair, and nuclei in quiescent disease that are larger than expected for that disease state (Guindi \& Riddell, 2001). Once a lesion is classified as dysplastic it is further differentiated into (1) low grade dysplasia, (2) high grade dysplasia, and (3) carcinoma (Riddell et al., 1983). Because there is significant inter-observer variability among pathologists, the diagnosis of dysplasia must be confirmed by a second expert IBD pathologist. Histologically, low grade dysplasia is hallmarked by nuclear enlargement, increased nuclear to cytoplasmic ratio, hyperchromasia, pleomorphisms, and increased mitoses. Classically, the nuclei are limited to the basal half of the cell cytoplasm. High grade dysplasia is similar to low grade dysplasia histologically, but more severe. It has prominent nuclear stratification and nuclei that are larger with more open nuclear chromatin patterns compared to low grade dysplasia. Unlike low grade dysplasia, the mitoses are both more frequent and present in the upper levels of the crypts as well as the surface epithelium. Additional general characteristics include: hyperchromatism, crowding, pleomorphism, loss of polarity of nuclei, and architectural aberrations like back to back gland patterns and cribriforming of the crypts (Farraye et al., 2010; Guindi \& Riddell, 2001). This category of high grade dysplasia also includes carcinoma in situ, but it is not differentiated in reports (Itzkowitz \& Harpaz, 2004). Carcinoma is defined by the presence of cells or glands that penetrate through the lamina propria and or submucosa. In UC-related carcinoma, single cell and small gland infiltration or large dysplastic crypts with irregular jagged contours or a complex cribriform gland pattern are seen. Also commonly seen features include necrosis, hemorrhage, ulceration, and desmoplasia. Ultimately, when determining the degree of dysplasia, pathologists assign the level based on the most severe level of atypical portion found in the biopsy sample (Farraye et al., 2010).

\subsection{Dysplasia classification systems}

While the United States uses the Ridell based classification of dysplasia (negative, indefinite, low or high grade dysplasia), outside the US, the Vienna system is used. This system was developed to improve standardization of interpretation and terminology of dysplasia. It is slightly different than Ridell's classification and uses a five category system. The five categories are: negative for neoplasia/dysplasia, indefinite for neoplasia/dysplasia,

\begin{tabular}{|c|c|}
\hline Vienna & Riddell \\
\hline $\begin{array}{l}\text { 1. Negative for neoplasia/dysplasia } \\
\text { 2. Indefinite for neoplasia/dysplasia } \\
\text { 3. Noninvasive low grade neoplasia } \\
\text { 4. Noninvasive high grade neoplasia } \\
\text { a. High grade adenoma/dysplasia } \\
\text { b. Noninvasive carcinoma } \\
\text { c. Suspicious of invasive carcinoma } \\
\text { 5. Invasive neoplasia } \\
\text { a. Intramucosal adenocarcinoma } \\
\text { b. Submucosal carcinoma or beyond }\end{array}$ & $\begin{array}{l}\text { 1. Negative for dysplasia } \\
\text { 2. Indefinite for dysplasia } \\
\text { 3. Low grade dysplasia } \\
\text { 4. High grade dysplasia }\end{array}$ \\
\hline
\end{tabular}

Table 3. Riddell and Vienna classification systems 
noninvasive high-grade neoplasia, and invasive neoplasia. The last two categories are further sub-classified histologically (see table 3 for full details) (Schlemper et al., 2000). Clinically though, there are no important differences between the two classification systems.

\subsection{Risk of cancer based on degree of dysplasia}

Given that the presumed stepwise sequence of developing CRC in UC is inflammation to low grade dysplasia to high grade dysplasia to carcinoma, the risk of progression from levels of dysplasia is important to quantify to help determine surveillance recommendations. Indefinite for dysplasia has classically been considered to be noncancerous. However, newer studies question if the malignancy risk is underestimated. According to some studies, indefinite for dysplasia should be considered to behave like the subcategory low grade dysplasia (Bernstein et al., 1994). The progression from indefinite dysplasia to CRC ranged from 9\% to $28 \%$ (Bernstein et al., 1994; Rutter et al., 2006; Ullman et al., 2008). In low grade dysplasia, the overall risk of cancer is reported as a $10 \%$ risk of invasive carcinoma (axon, 1994; Bernstein et al., 1994). Unfortunately in high grade dysplasia the risk is even greater, increasing to nearly $40 \%$ (Bernstein et al., 1994).

\begin{tabular}{|l|l|}
\hline Dysplasia & Risk of CRC \\
\hline High grade dysplasia & +++ \\
Low grade dysplasia & ++ \\
Indefinite for dysplasia & Questionable risk (could be similar to low grade dysplasia) \\
Negative for dysplasia & No risk \\
\hline
\end{tabular}

Table 4. Type of dysplasia and risk of CRC

\subsection{Dysplastic associated lesions or masses (DALM)}

Dysplasia is further sub-classified as flat or elevated lesions (Itzkowitz \& Harpaz, 2004). Flat dysplasia is undetectable endoscopically but picked up by random biopsies, while raised is visualized and referred to as "DALM" (dysplastic associated lesion or mass) (Blackstone et al., 1981). DALMs are visible dysplastic lesions with an unacceptably high risk of carcinoma. In a series by Blackstone et al., 58\% of these lesions had an underlying carcinoma

\begin{tabular}{|l|l|}
\multicolumn{1}{|c}{ Adenoma-like DALMs } & \multicolumn{1}{c|}{ Non-adenoma-like DALMs } \\
\hline Sessile/pedunculated polyps & Sessile (broad based) \\
Well circumscribed & Poorly circumscribed \\
Smooth & Irregular surface \\
Clear borders & Indistinct border \\
& Ulceration/necrosis \\
& Strictures \\
& Tethering \\
\hline
\end{tabular}

Table 5. Features of DALMs

(Blackstone et al., 1981). Others studies, report underlying carcinomas ranging from $34 \%$ to 84\% (Bernstein et al., 1994; Odze, 1999). DALMs can be further sub-classified into adenoma- 
like and non-adenoma-like features (Engelsgjerd et al., 1999; Odze et al., 2004; Rubin et al., 1999). Adenoma-like features include well circumscribed, smooth or papillary, non-necrotic, sessile, or pedunculated polyps. Non-adenoma-like polyps include velvety patches, plaques, irregular bumps or nodules, wart-like thickening, stricturing lesions, and broad-based masses (Odze, 2008). The differentiation between adenoma-like and non-adenoma-like is based on gross endoscopic examination. Histologically both types of DALMs are made of tubular, tubulovillous or villous proliferation of adenoma epithelium with dysplastic columnar cells (Torres et al., 1998).

\subsection{Treatment of DALMs}

One of the challenges related to DALMs is the reliance on the endoscopist to differentiate adenoma-like lesions from a sporadic adenoma. Like the general population, sporadic adenomas increase with age and can be removed via polypectomy. However, some DALMs can develop features similar to a sporadic adenoma making it further difficult to differentiate the two (Guindi \& Riddell, 2001; Torres et al., 1998). While there have been studies to differentiate sporadic adenomas from DALMs in UC patients, most did not achieve a level of certainty to confidently differentiate them (Bernstein et al., 1999; Torres et al.. 1998). The only aspect that seems to differentiate the two in UC are that adenoma-like lesions proximal to the start of the UC are likely sporadic adenomas (Torres et al., 1998).

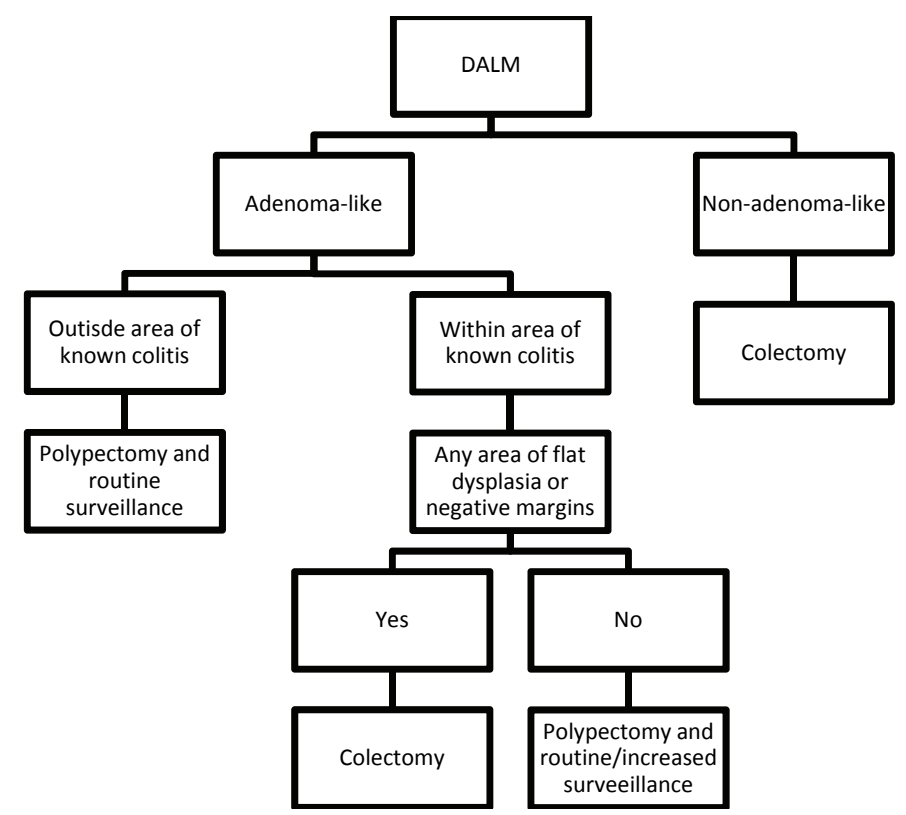

Fig. 1. Treatment algorithm for DALMs

Until recently, treatment differed between sporadic adenomas and adenoma-like DALMs for which colectomy had been recommended. Thirty four patients with adenoma-like DALMs who underwent polypectomy were compared both to UC patients with sporadic adenomas who underwent polypectomy and non-UC patients with sporadic adenomas who 
underwent polypectomy. The development of recurrent polyps was $62.5 \%$ in the adenomalike DALM group, $50 \%$ in UC sporadic adenoma group and $49 \%$ in the non-UC sporadic adenoma control group (Engelsgjerd et al., 1999). In another study of eighty seven UC patients who underwent polypectomy, only $4.6 \%$ developed dysplasia during a mean follow up of six years (Vieth et al., 2006). Given that polypectomy for adenoma-like DALMs in UC patients affords similar protection against CRC as polypectomy for sporadic adenomas, current consensus recommendations support polypectomy for DALMs. Therefore, if an adenoma-like DALMs is completely resected endoscopically, with negative margins for dysplasia from biopsies around the lesion and no other findings of flat dysplasia in the colon, then routine surveillance following polypectomy is appropriate (Friedman et al., 2003; Odze et al., 2004; Rubin et al., 1999). Similarly, any adenoma-like lesions outside the area of UC can be presumed to be sporadic in nature and treated with polypectomy and routine surveillance alone (Friedman, 2003). For adequate follow up surveillance, tattooing the adjacent mucosa to the resected polyps can aid in future identification and monitoring.

In contrast, non-adenoma-like DALMs carry an unacceptable cancer risk (38\% to $83 \%$ ) even in those lesions considered endoscopically resectable. Therefore, any non-adenoma-like DALMs regardless of their sub-classification as low or high grade dysplasia necessitate colectomy.

\subsection{Flat dysplasia}

In cases of flat dysplasia, it is important to differentiate between high and low grade dysplasia. In small studies, high grade flat dysplastic lesions had concurrent CRC in $42 \%$ to $67 \%$ of cases (Bernstein et al., 1999; Connell et al., 1994; Hata et al., 2003). In another study, patients who underwent colectomy for high grade dysplasia, $45 \%$ were found to have CRC noted on pathology (Rutter et al., 2006). In patients with high grade dysplasia who chose not to undergo colectomy, $25 \%$ to $32 \%$ of the cases progressed to CRC (Bernstein et al., 1999; Rutter et al, 2006). Given the high risk for synchronus CRC associated with high grade dysplastic lesions, and the significantly increased risk of progression to CRC, current consensus opinions recommends colectomy.

With regards to low grade flat dysplasia, however, the evidence is more equivocal. Low grade dysplasia can be viewed as an intermediate step in the development of CRC, or it alone may be a marker for synchronous undiagnosed high grade dysplastic lesions or cancer. (Bernstein et al., 1994; Gorfine et al., 2000; Rutter et al., 2006). Studies vary regarding the risks of low grade dysplasia with some equating it to the risk of high grade dysplasia while others find it no more concerning than patients with no dysplasia. Small studies including patients who underwent colectomy for low grade dysplasia found synchronous CRC in 19\% to 27\% of patients (Bernstein et al., 1994; Farraye et al., 2010; Rutter et al., 2006). A more recent meta-analysis by Thomas et al. included 20 surveillance studies of flat low grade dysplasia or low grade dysplasia DALMs, and found a cancer incidence of 14 per 1000 patient years and 30 per 1000 patient year incidence of advanced lesions (high grade dysplasia or CRC). When low grade dysplasia was detected on colonoscopy it was associated with a nine fold increased risk of developing CRC, and 12 fold risk of developing advanced lesions. For patients who opt to avoid colectomy and prefer continued surveillance of flat dysplasia, according to this meta-analysis the positive 
predictive value for progression to high grade dysplasia or CRC is approximately $14.6 \%$ (Thomas et al., 2007). Other studies list rates of progression to neoplasia ranging from $33 \%$ to 54\% (Rutter et al., 2006; Ullman et al., 2002). Other studies suggest that the risk of progression from low grade dysplasia to high grade dysplasia or CRC is actually much lower. In a study of patients with long standing extensive UC, the risk of progression to CRC in patients with low grade dysplasia was $10 \%$ while patients with extensive UC but no dysplasia progressed to CRC in $4 \%$ of the cases. This study concluded that the risk of progression is not much higher than in patients with no dysplasia (0.8 to $3 \%)$ and therefore prophylactic colectomy is not appropriate (Lim et al., 2003). Moreover, another study did not find any cases of low grade dysplasia progressing to CRC (Befrits et al., 2002). Since the actual risk of progression is unclear, consensus recommendations favor discussion with the patients and informing them of the risks and benefits of surveillance versus early colectomy. A medical decision analysis of 10,000 patients with UC was performed to assess patient preference when faced with the decision between surveillance and colectomy for unifocal low grade dysplasia. Overall patients preferred immediate colectomy, with slight increase in quality adjusted life years and overall lower costs of treatment (Nguyen et al., 2009).

\subsection{Prevalent versus incident dysplasia}

Dysplasia is further classified based on when it was found on endoscopic exam. Dysplasia detected on initial colonoscopy is referred to as prevalent dysplasia. Prevalent dysplasia carries a higher rate of progression to CRC. When prevalent low grade dysplasia was found $29 \%$ of patients progressed to high grade dysplasia or CRC during follow up (Bernstein et al., 1994). In contrast, dysplasia that was detected on subsequent surveillance colonoscopy is referred to as incident dysplasia. When incident low grade dysplasia was found, only $16 \%$ of cases progressed to high grade dysplasia or CRC. In comparison, if no dysplasia was noted on initial colonoscopy, the risk of subsequent CRC ranged from $1.1 \%$ to 3.1\% (Bernstein et al., 1994; Connell et al., 1994; Lindberg et al., 1996; Nugent et al., 1991).

\subsection{Interobserver variability in grading of dysplasia}

Unfortunately, there is significant variability in pathologists' agreement in the grading of dysplasia, ranging from 42 to 65\% (Melville et al., 1989). This is most prominent in nongastrointestinal specialized pathologists and between the classification of marked regenerative changes versus low grade dysplasia and between the classification of high grade dysplasia and invasive adenocarcinoma (Riddell et al., 1983). Interobserver studies show only moderate levels of agreement between pathologists' interpretations (Dixon et al., 1988; Eaden et al, 2001b; Melville et al., 1989; Odze et al., 2002). The levels of agreement were lowest in cases of indefinite dysplasia and low grade dysplasia. Unfortunately, even with experienced pathologists, there still remain a significant amount of interobserver variability between indefinite versus low grade (Melville et al., 1989). In contrast, the interobserver validity between negative and high grade dysplasia is quite good (Dixon et al., 1988). Given that treatment decisions are made based on the degree of dysplasia, consensus recommendations recommend that a pathologist specializing in gastroenterology review and confirm any cases of dysplasia (Itzkowitz \& Present, 2005). 


\begin{tabular}{|l|l|}
\hline Levels of dyplasia & \multicolumn{1}{|l|}{ Interobserver validity } \\
\hline Indefinite for dysplasia vs. Low grade dysplasia & Poor \\
High grade dysplasia vs. Carcinoma & Poor \\
Negative for dysplasia vs. High grade dysplasia & Good \\
\hline
\end{tabular}

Table 6. Interobserver validity based on level of dysplasia

\subsection{Molecular markers}

In order to reduce interobserver variability molecular and non-molecular markers have been evaluated to aid in the diagnosis of dysplasia. Majority of the studies on tumor markers are tested from the biopsy samples of dysplasia or no dysplasia which unfortunately does not provide information on the evolution of the dysplasia. Few studies have been designed to study patients longitudinally over time to detect the early expression of tumor markers. The markers that have been evaluated in this format showing increased risk of CRC include aneuploidy, p53, MSI and mucin-associated STn antigen (Farraye et al., 2010). Aneuploidy is an early event in the carcinogenesis pathway often occurring before or coincident with the initial detection of dysplasia (Rubin et al., 1992). Similarly, p53 mutation is also an event that is likely preceding the dysplasia and is an important step in the carcinogenesis progression (Lashner et al., 1999). In some of the patients the p53 mutation was detected eight months to two years prior to dysplastic changes (Ilyas \& Talbot, 1995; Lashner et al., 1999). Patients with this mutation had a relative risk of developing dysplasia or cancer of 4.53 (95\% CI 2.169.48) and was associated with cancer related mortality (Lashner et al., 1999). Likewise, patients who develop microsatellite instability CRC already expressed these changes in nondysplastic tissue ranging from two to twelve years prior to the diagnosis of CRC (Tahara et al., 2005). The STN antigen expression occurs frequently in dysplastic lesions that often occur earlier than the aneuploidy changes (Karlen et al., 1998b). While these markers seem to portend a poor prognosis like p53, they are not incorporated yet into the overall assessment to choose between colectomy and continued surveillance. The added benefits of these makers are their noted presence in the mucosa long before carcinoma develops. Such an aid could assist pathologists in being more precise in their grading of dysplasia. However, further studies are still needed to determine the niche of molecular profiling in CRC surveillance and risk stratification.

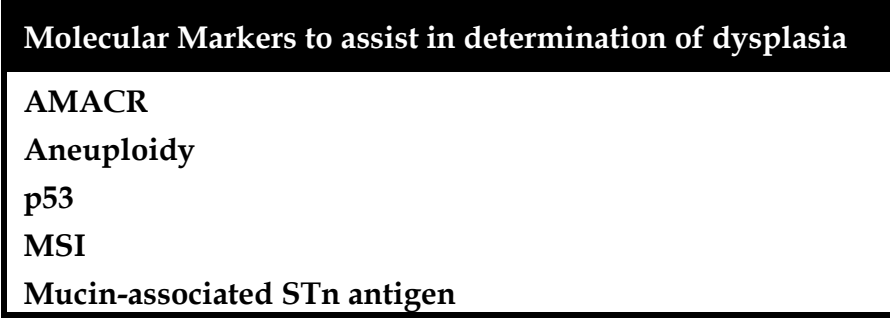

Table 7. Potential molecular markers to aid in determination of dysplasia

A potentially promising biomarker is the a-methylacyl-CoA racemase (AMACR). This marker is not found in any non-dysplastic tissue. It is significantly increased in areas of low 
grade dysplasia (96\%), high grade dysplasia $(80 \%)$ and adenocarcinoma $(71 \%)$. This marker was only found in $14 \%$ of cases of indefinite for dysplasia, but was only focally and weakly positive. In attempting to differentiate high grade dysplasia the specificity is nearly $100 \%$ with a sensitivity of 80 to $96 \%$ (Dorer \& Odze, 2002). While more studies are still needed, this marker does have the potential to significantly assist pathologists in determination of dysplasia versus no dysplasia.

\section{Surveillance colonoscopy}

While enhanced surveillance colonoscopy in patients with UC is presumed to reduce the risk of developing CRC, it has not been proven through randomized control trials. Only case series suggest a possible benefit (Eaden et al., 2000a; Lofberg et al., 1990; Nugent et al., 1991). A Cochrane database review of these trials in 2004 revealed a reduction in CRC mortality in those patients who underwent at least one screening colonoscopy with a relative risk of 0.28 (95\% confidence interval 0.07 to 1.17). This effect was more pronounced in those who had at least two screening colonoscopies (RR 0.22 95\% confidence interval 0.03 to 1.74). This effect was less notable for patients who only had one colonoscopy (RR $0.4395 \%$ confidence intervals 0.05 to 3.76). Unfortunately though, all the confidence intervals crossed 1 . As a result, the study concluded that there is no clear evidence that surveillance colonoscopy prolongs patient survival. While cancer is detected at an earlier stage in patients with a better prognosis who undergo surveillance screening, there is concern that lead time bias may cause this affect. It seems likely, though, that screening reduces the risk of death and may be cost effective as well. (Mpofu et al., 2004).

\subsection{Surveillance colonoscopy recommendations}

While classic CRC screening recommends colonoscopy once every ten years given the slow evolution of adenoma to carcinoma, in UC this interval is less clear. Some studies have noted new pathology within one to two years of a reported negative colonoscopy (Connell et al., 1994; Lim et al., 2003). Therefore, surveillance colonoscopy initiation and interval follow up is tailored to the patients underlying risks. All patients with UC should undergo a screening colonoscopy at eight years to ten years after the onset of symptoms with appropriate biopsies to determine the true extent of any microscopic disease (Eaden \& Mayberry, 2002).

Extent of disease, which helps determine follow up interval, is based on the most proximal disease noted histologically at any point in the patient's disease. If the patient's disease is isolated proctitis or proctosigmoiditis then UC specific related screening can be terminated. As mentioned earlier, these isolated conditions do not convey a significantly increased risk of UC-related CRC. These patients should follow routine screening CRC prevention guidelines starting at age 50 unless the patient has a concerning family history necessitating earlier screening as per CRC screening guidelines.

If the UC is classified as pancolitis or left sided colitis with negative initial screening, the follow up colonoscopies should be performed every one to two years. In patients who have a negative initial screening colonoscopy, follow up exams should be performed every one to two years until the patient has two negative examinations. After two negative exams, surveillance can be spread to over one to three years until the duration of disease has existed for twenty years. At that time, interval surveillance should be narrowed again to every one to two years. 
Patients with associated primary sclerosing cholangitis carry a significantly increased risk of CRC and therefore should begin indefinite screening immediately at the time of diagnosis and every year thereafter. Other high risk patients, like those with a family history of CRC in first degree relatives, ongoing active inflammation (either endoscopic or histologic), foreshortened colon, strictures, or multiple inflammatory pseudopoyps all may benefit from more frequent surveillance exams. However, the exact interval follow up is unclear (Farraye et al., 2010; Itzkowitz \& Present, 2005).

\begin{tabular}{|l|l|}
\multicolumn{1}{|c}{ Initial screening colonoscopy } & \multicolumn{1}{c|}{ Screening recommendations } \\
\hline Ulcerative colitis screening colonoscopy & Initiate 8-10 years after onset of disease \\
\hline Associated Primary sclerosing cholangitis & Initiate at time of diagnosis \\
\hline $\begin{array}{l}\text { Interval follow up screening after initial } \\
\text { negative screening colonoscopy }\end{array}$ & $\begin{array}{l}\text { Continue surveillance intervals every 1-2 } \\
\text { years until 2 negative exams } \\
\text { then interval screening is every 1-3 years. }\end{array}$ \\
\hline UC patient with negative initial screen & $\begin{array}{l}\text { Re-start surveillance intervals every 1-2 } \\
\text { years }\end{array}$ \\
\hline UC patient with 20 years duration of disease & $\begin{array}{l}\text { Continue regular surveillance intervals } \\
\text { every 1-2 years }\end{array}$ \\
\hline UC patient with Extensive/Left sided colitis & Continue surveillance every year \\
\hline UC patient with PSC & $\begin{array}{l}\text { May benefit from more frequent } \\
\text { surveillance. Exact interval surveillance } \\
\text { is unclear. }\end{array}$ \\
\hline $\begin{array}{l}\text { UC patient with family history of CRC, active } \\
\text { inflammation, foreshortened colon, strictures, } \\
\text { multiple inflammatory pseduoplyps }\end{array}$ & $\begin{array}{l}\text { Screen per guidelines for age-specific } \\
\text { CRC (no increased surveillance) }\end{array}$ \\
\hline $\begin{array}{l}\text { UC patient with isolated } \\
\text { Proctitis/Proctosigmoiditis }\end{array}$
\end{tabular}

Table 8. Summary of screening and follow up surveillance recommendations

The British Society of Gastroenterology updated their screening recommendations in 2010. The updates to their guidelines include initiating screening approximately ten years after disease onset. Also, surveillance colonoscopies should only be performed during disease remission, but should not be unduly delayed. Importantly, the risk of cancer is influenced by duration and extent of disease and additional risk factors like primary sclerosing cholangitis and family history of colorectal cancer. Also, both histologic and endoscopic features can also portend an increased risk of CRC. Patients at high risk should have yearly exams, moderate risk every three years, and low risk every five years. Newer modalities of screening are also incorporated in the new guidelines. Pancolonic dye spraying with targeted biopsies of the abnormal area should be performed. If chromoendoscopy is available then it should be used. Otherwise two to four random biopsies of every $10 \mathrm{~cm}$ of colon should be obtained. However, in areas of concern, additional biopsy samples should be taken. Finally, if dysplastic lesions can be completely removed it is not necessary to recommend colectomy (Cairns et al., 2010). 


\subsection{Management of dysplastic lesions}

In the event that flat high grade dysplasia is noted anywhere in the colon and confirmed by an expert gastrointestinal pathologist, colectomy is the treatment of choice (Farraye et al., 2010; Thomas et al., 2007). Similarly, multifocal low grade dysplasia is also considered a strong indication for colectomy. Those with pathology termed indefinite for dysplasia should undergo a repeat examination in three to twelve months (Farraye et al., 2010). It is unclear if colectomy or enhanced surveillance should be performed for flat unifocal low grade dysplasia given the potential progression to high grade dysplasia or CRC. If surveillance is chosen, follow up colonoscopy should be done within three to six months. Discussion about risks and benefits of colectomy versus closer surveillance must be discussed with the patient. Similarly, it is unclear if recurrent findings of flat low grade dysplasia on serial colonoscopies increase the risk of synchronous or metachronous CRC compared to the risk associated with the finding of an isolated flat low grade dysplasia. A similar discussion with the patient regarding risks and benefits of screening versus colectomy should be done.

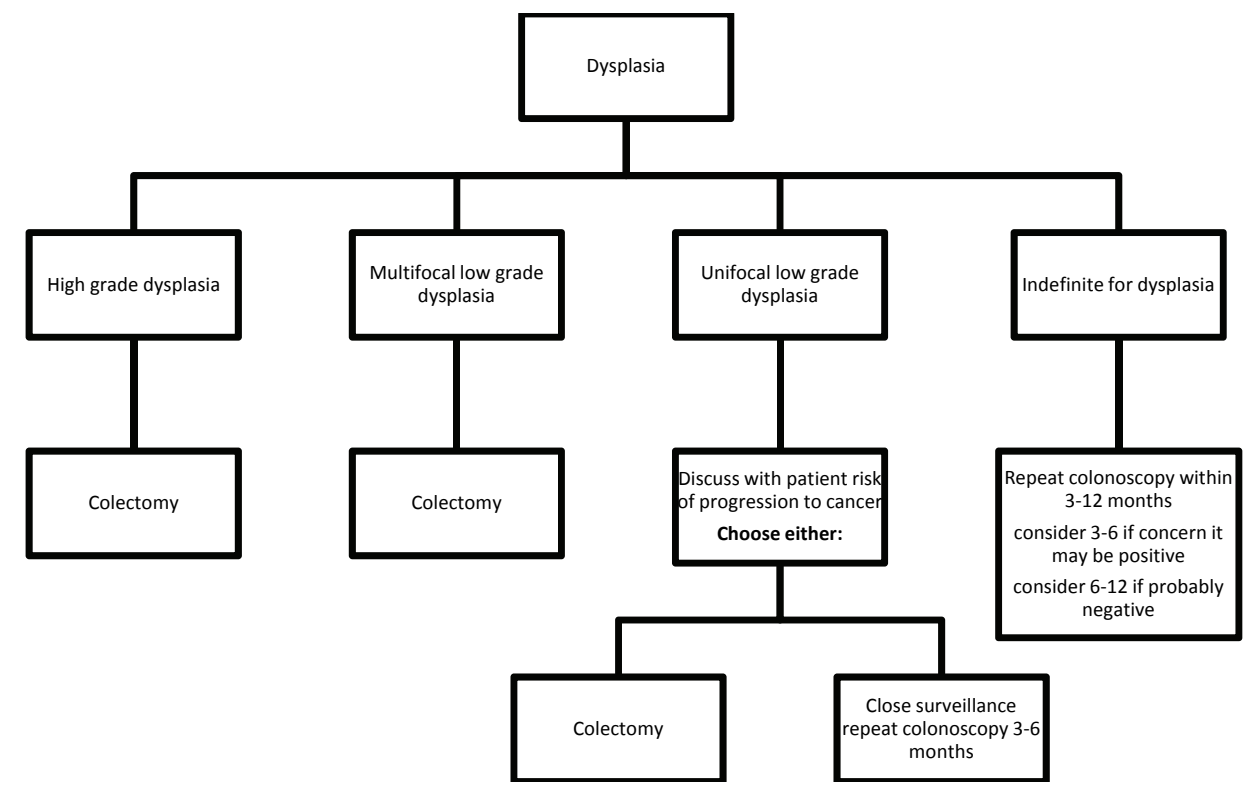

Fig. 2. Management of dysplasia (For DALM management see figure)

\subsection{Factors involving successful endoscopy}

There are a number of factors that affect the success rate of a screening colonoscopy program. The initial detection of potentially dysplastic lesions relies on endoscopist skill and technique. Unlike sporadic adenomas, some lesions in UC may be flat and difficult to detect. Overall though, up to two thirds of dysplastic lesions are visible on endoscopy (Rutter et al, $2004 b$ ). However, a sizable number of potentially dysplastic lesions are missed on routine endoscopic visualization. As a result, a number of newer techniques are being developed to enhance the detection of the remaining dysplastic lesions. Another challenge is the ability to 
completely resect suspected lesions. While prior studies had recommended colectomy for DALMs, newer studies have demonstrated equal success with complete polypectomy (Engelsgjerd et al., 1999; Vieth et al., 2006). The importance of complete resection is crucial to the success of a surveillance program. Any lesion that cannot be completely resected, should negate continued surveillance and proceed to colectomy. Lastly, the endoscopic must comply with the current consensus recommendations when using their recommended intervals. Overall adherence to consensus guidelines is quite poor (Bernstein et al., 1995; Eaden et al., 2000b).

\subsection{Adequate sampling of mucosa}

Given that microscopic disease can occur anywhere in the colon, multiple biopsies must be obtained to achieve adequate surveillance. Thirty three samples yielded a $90 \%$ probability of detecting any present dysplasia, while sixty four samples yield a 95\% probability of detecting dysplasia if present (Rubin et al., 1992). A total of two to four samples should be taken from all four quadrants from every ten centimeters of colon (Itzkowitz \& Harpaz, 2004). Careful examination and sampling of the rectosigmoid region is crucial as this area has a predominance of neoplasia in UC (Choi, 1993). These specimens should be collected in individual jars to assist in localizing the specimen back to the colonic segment if further monitoring is warranted. The ideal time for surveillance screening with random biopsy sampling should be when the patient is in a state of clinical remission. Active inflammation creates difficulty in distinguishing reactive epithelium from dysplasia (Eaden \& Mayberry, 2002). Nonetheless, even with extensive biopsies of the colon, it is still only a small fraction of the entire colon that is sampled (approximately 1\%) (Itzkowitz \& Harpaz, 2004). Given that dysplasia is most often unifocal in nature, it is still quite possible to miss the one location that has high grade dysplasia or carcinoma. Another complicating factor is that despite consensus recommendations regarding biopsy sampling, surveys of gastroenterologists' biopsy practices in the United States and United Kingdom demonstate poor adherence to these recommendations, further lowering the probability of detecting dysplasia (Bernstein et al., 1995; Eaden et al., 2000c). As newer endoscopic modalities like chromoendoscopy and narrow band imaging are being developed, more targeted biopsies will be possible with the goal of overall improved surveillance of the entire colon.

\subsection{Anatomic factors complicating surveillance}

Adequate surveillance is also limited by anatomic factors. Presence of either psuedopolyps or strictures has been reported to increase the risk of CRC by two fold and four fold respectively (Rutter et al., 2004c). Other reports found up to $24 \%$ of strictures may be malignant (Gumaste et al., 1992). Additionally, strictures throughout the colon may limit the endoscopists ability to adequately maneuver around them limiting the comprehensiveness of the surveillance examination.

\section{Assessment, cost and safety, and hurdles to successful screening program}

The key features of any surveillance program include (1) a disease with a high prevalence in the selected patient population; (2) a screening test that is highly sensitive and specific, (3) low cost, (4) safe, and (5) acceptable to both the patient and the practitioner. The early 
detection of disease should then enable early treatment of the disease to ideally prolong survival (Wilson, \& Jungner, 1968). The prevalence of UC associated CRC, and the knowledge that dysplastic changes occur in the colon prior to symptoms provides the background for instituting a screening program. However, the costs, risks and associated hurdles all need to be evaluated for the program to be effective.

\subsection{Assessment of surveillance programs}

Evaluating the success of surveillance programs has been challenging for numerous reasons. The timeframe needed to assess the impact on patients requires approximately fifteen to twenty years (Eaden \& Mayberry, 2000). Also, patient compliance over this prolonged period of time is challenging, necessitating multiple visits for follow up colonoscopies. Another confounder is varying treatment recommendations from physicians. As discussed previously, adherence to guideline recommendations is variable. There are some centers that recommend early colectomy for dysplasia resulting in overall lower rates of cancer but at a significant morbidity cost. Finally, randomization is impractical given the ethical issues related to placing high risk patients in control arms (Eaden \& Mayberry, 2000). While some studies of screening endoscopies found earlier cases of cancer, this was only in a minority of patients with a high cost-to-benefit ratio (Axon, 1994; Collins et al., 1987; Gyde, 1990). Conversely, a small US study attributed early cancer detection to surveillance with a five year survival rate of $77 \%$ in the surveillance group compared to $36 \%$ in the control group (Choi, 1993). Other studies that did not find any significant benefit in detection of CRC still found a much lower mortality in the screened group due to associated clinical reviews of their disease and management (Connell et al., 1993; Karlen et al., 1998a). However, a Cochrane meta-analysis failed to show a benefit for surveillance screening colonoscopies to prevent CRC-related death (Rutter et al., 2006).

\subsection{Safety and cost effectiveness of surveillance}

The overall morbidity associated with surveillance colonoscopy is extremely low. The overall complication rate after 379 surveillance colonoscopies was one silent perforation, or 0.26\% (Koobatian \& Choi, 1994). Similar findings were noted in a British study of 811 surveillance colonoscopies (Lennard-Jones et al., 1990). Using decision analysis to provide indirect evidence of CRC screening effectiveness, Provenzale et al found life expectancy increased 1.2 years with screening (Provenzale et al., 1995). The overall cost of the surveillance program is difficult to estimate. The costs of the surveillance program need to include not only the medical costs, but also the patients time undergoing the test, travel, lost earnings, and, the more difficult to assess, patient anxiety and discomfort (Eaden \& Mayberry, 2000). One US study using a hypothetical scenario of a screening system that found all cancerous lesions in 1000 patients over a ten year period estimated the cost for each cancer found or prevented to be $\$ 200,000$ (based on cost data from 1983). However, this price does not account for the patient costs or potential complications when performing the numerous colonoscopies. In this study, an estimated 9,775 colonoscopies were performed to locate or prevent a cancer. However, with a perforation rate of 0.2 to 0.4 roughly three patients would need emergent treatment for perforated colon adding to the overall screening cost (Collins et al., 1987; Eaden \& Mayberry, 2000; Katzka et al., 1983). A more recent study comparing endoscopic cancer screening tests found a theoretically lower cost. Using an estimated risk of UC related CRC of $1 \%$, and with performingcolonoscopies every 
two years, they found that 1.4 to 2 cancers per 100 endoscopies would be detected. The overall cost of the procedure alone was $\$ 71,000$ per cancer detected (Sonnenberg \& El-Serag, 1997). Unfortunately, these numbers are only hypothetical costs of the procedures alone in a $100 \%$ successful screening system.

\subsection{Hurdles to successful screening surveillance program}

Crucial to any screening program is the ability of the endoscopist to accurately biopsy the colon and the pathologist to accurately diagnose dysplasia. Discussed early in this chapter, the interobserver variability amongst pathologists can limit the successful diagnosis of dysplasia and appropriate treatment recommendations. Furthermore, despite consensus guidelines published by both European and US societies, there still remains significant variability amongst gastroenterologists' compliance with these recommendations. In one study of US gastroenterologists, only 19\% correctly defined dysplasia. Within this group $48 \%$ accurately defined high grade dysplasia and only $16 \%$ defined low grade dysplasia. When choosing treatment options, nearly one third of gastroenterologists recommended continued surveillance despite a diagnosis of high grade dysplasia (Bernstein et al., 1995). In a British study, only $53 \%$ of gastroenterologists recommended colectomy for high grade dysplasia (Eaden et al., 2000b). A more recent study of both colorectal surgeons and gastroenterologists from New Zealand similarly found poor knowledge of the definition of dysplasia, with only $20 \%$ responding correctly. In this group, the colorectal surgeons defined dysplasia correctly more often and understood the significance of low grade dysplasia as well (Geary et al., 2004). Despite clear recommendations from the American Gastroenterological Association to perform four quadrant biopsies every ten $\mathrm{cm}$ for a total of thirty to forty biopsies, only $41 \%$ of gastroenterologists followed this recommendation. $52 \%$ of the gastroenterologists only took two to four biopsies and $6 \%$ did not follow any protocol. Overall, $73 \%$ of the gastroenterologists performed less than thirty biopsies per colonoscopy (van Rijn et al., 2009) . In assessing the overall adequacy of surveillance, 33\% of patients received inadequate surveillance for CRC (Reddy et al. 2005; Obrador et al., 2006). In 2009, Kottachchi et al. performed a retrospective study after the publication of the Canadian Association of Gastroenterology screening guidelines and found that the overall adherence improved with $74 \%$ of patients receiving follow up surveillance appropriately (Kottachchi et al., 2009). Ultimately, the overall education and continued education in association with consensus guidelines is crucial to adequate screening.

\subsection{Patient adherence}

Another major hurdle to successful surveillance is patient acceptance of the surveillance process. Multiple aspects of the screening program can create challenges for patients to comply with the screening. Close follow up colonoscopies require patients to repeat bowel preparations, return to clinic, and find a chaperone to take them home. All of these steps are potential pitfalls for patient compliance. Unfortunately, most of these steps cannot be altered to improve patient compliance. However, studies evaluating patient compliance in routine CRC screening found a positive association between knowledge and screening behavior (Vernon, 1997). The lack of knowledge is most prominent among minorities and those of low socioeconomic status (Beeker et al., 2001; Lipkus et al., 1996; Price, 1993). Patients need counseling regarding the importance of CRC surveillance as well as the understanding of the predictive value of the colonoscopy to effectively rule out potential cancer. 
Unfortunately, if patients do not adhere to the surveillance recommendations negative consequences may occur (Connell et al., 1994; Lindberg et al., 1996).

\begin{tabular}{|l|}
\hline Barriers to screening \\
Definition of dysplasia \\
Differentiating subtypes of dysplasia \\
Appropriate number of biopsies \\
Adherence to guidelines \\
Surveillance \\
Treatment \\
Patient specific barriers \\
Lack of knowledge \\
Preferences \\
Non-compliance with recommendations
\end{tabular}

Table 9. Barriers to screening

\section{Newer imaging modalities}

Given that up to $1 / 3$ of dysplasia is not detected on endoscopic examination, better diagnostic modalities are needed in place of just random biopsies. Without improved diagnostic techniques, a negative exam from random biopsies could convey a false sense of reassurance. Newer modalities attempt to delineate those lesions that are subtle but present at the layer of the mucosa, or even deeper providing the endoscopist with both subsurface analysis and instant histologic analysis. Such newer techniques combining both random biopsies with more focused examination would theoretically provide a more thorough and accurate screening process. Newer modalities are sometimes used alone or in combination and include chromoendoscopy with pancolonic dye spraying, autofluorescene, confocal laser endomicroscopy, narrow band imaging, and optical coherence tomography.

\subsection{Chromoendoscopy}

Chromoendoscopy is a technique that has already been used in Europe and Asia, and more recently in the US, to help identify non-polypoid flat and depressed potentially neoplastic lesions (Soetkino et al., 2006). Chromoendoscopy involves applying mucosal stain or pigment by injecting dye down an endoscopic spray catheter. Indigo carmine is one type of dye which coats the colonic mucosal surface enabling the endoscopist to visualize subtle disruptions in the normal contours of the mucosa. Another dye, methylene blue, is avidly absorbed by non-inflamed mucosa and poorly taken up by inflamed mucosa and dysplastic lesions. The dyes improve the detection of subtle colonic lesions enabling increased sensitivity of screening colonoscopy. Additionally, chromoendoscopy can differentiate neoplastic from non-neoplastic lesions based on the crypt architecture utilizing the modified pit pattern classification (Rutter, 2010). This is further improved when using a magnifying colonoscope (Kudo et al., 2001). These techniques enable the endoscopist to obtain targeted biopsies after pancolonic dye spraying, improving overall sensitivity of the exam (Kiesslich et al., 2003; Marion et al., 2008; Mastumoto et al., 2003; Rutter et al., 2004a). 
Chromoendoscopy is also able to provide a more accurate determination of extent of disease as well as degree of inflammation (Kiesslich et al., 2003). The superiority of focused biopsies utilizing methylene blue was supported in a study noting a three fold increase in dysplasia detection compared to random biopsies alone (Kiesslich et al., 2003). In comparing the diagnostic yield to standard colonoscopy, panchromoendoscopy with indigo carmine dye increased the diagnostic yield of dysplasia 3.5 to 4.5 fold (Rutter et al., 2004a). A different study compared 350 patients with long standing UC undergoing surveillance using chromoendoscopy and a high magnification colonoscope to 350 matched UC control patients undergoing standard white light colonoscopy and found that the enhanced screening technique yielded more dysplastic lesions. However, this enhanced detection was at the cost of significantly longer extubation times (average of 24 minutes compared to 13 minutes in the control group) (Hurlstone et al., 2005).

\subsection{Autofluorescene imaging}

A different imaging enhanced modality, autofluorescene imaging, in a small study showed improved detection of dysplastic lesions compared to routine endoscopy (van den Brock et al., 2008). The sensitivity for detecting dysplastic lesions ranged from $87 \%$ to $100 \%$ after local sensitization (Kiesslich et al., 2008). However, current guidelines do not currently incorporate this method into their screening recommendations and more studies are needed to assess its overall utility and cost effectiveness.

\subsection{Confocal laser endomicroscopy}

A newer method, confocal laser endomicroscopy, allows subsurface analysis of intestinal mucosa and analysis of the underlying histology during the endoscopy (Kiesslich et al., 2008). This is attached to a standard endoscope and used in conjunction with a system fluorescent contrast agent or topical agent sprayed on mucosa. The images provide real-time information regarding cellular and vascular changes. The sensitivity reached $97.4 \%$ with a specificity of $99.4 \%$ and an accuracy of $99.2 \%$ (Kiesslich et al., 2007). This method can be used in conjunction with chormoenedoscopy which will help identify circumscript lesions, while the laser endomicroscopy is able to predict the intraepithelial neoplasias (Kiesslich et al., 2008). In a study comparing the combination of panchromoendoscopy and endomicroscopy compared to conventional colonoscopy, the combined modality found significantly more intraepithelial neoplasia (19 versus $3 \mathrm{p}$ value 0.007 ) but had an 11 minute longer average extubation time (42 minutes versus 31 minutes). This technique provided a 4.75 fold increase in detected dysplastic lesions while needing $50 \%$ fewer biopsy specimens (Kiesslich et al., 2007).

\subsection{Narrow band imaging, optical coherence tomography}

Other modalities like narrow band imaging which uses optical technology to visualize microvascular structures of the mucosal layers has not been shown to be superior to standard colonoscopy (Dekker et al., 2007). Another method, optical coherence tomography, utilizes an optical analog of ultrasound to allow for cross-sectional images of the luminal gastrointestinal tract. This too does not yet provide satisfactory resolution to enhance surveillance over routine colonoscopy (Kiesslich et al., 2008).

Given that all these techniques are still relatively new, it has not been proven yet if the increased sensitivity in locating dysplastic lesions in fact prolongs survival. Also, as white 
light endoscopy technology continues to improve, it is unclear how many additional lesions will still be found when newer white light endoscopes are studied in comparison to chromoendoscopy (Farraye et al., 2010).

\section{Chemoprevention}

In the non-UC population, chemoprevention using cox-2 inhibitors or aspirin has been evaluated with success (Arber \& Levin, 2008). In UC, chemoprevention is of particular interest for its potential to reduce the risk of CRC. Similar to sporadic CRC, the presumed initial insult is chronic inflammation. As a result, chemoprevention in UC has also focused on anti-inflammatory agents. Aminosalicylates, corticosteroids, folic acid, immunomodulators, and UDCA have all been studied.

\subsection{Ursodeoxycholic acid (UDCA)}

As mentioned earlier, UC patients with associated PSC are at the highest risk of CRC. UDCA is already used to treat the cholestatic affects of primary sclerosing cholangitis. Retrospective analysis of patients already taking UDCA and with concomitant UC found a strong decreased incidence of colonic dysplasia with an odds ratio of 0.18 (95\% CI 0.05-0.61) (Tung et al., 2001). This was confirmed in a prospective study out of Mayo Clinic showing a similar reduction in dysplasia and cancer (Pandi et al., 2003). Unfortunately though, there have been conflicting studies performed showing no chemopreventive effects from the UDCA (Shetty et al., 1999; Wolf et al., 2005). UDCA has also been evaluated in patients with UC with no associated PSC. A small study in Sweden found potential benefits after two years of treatment with UDCA; in the ten patients who took UDCA, none developed high grade dysplasia or cancer (Sjoqvist et al., 2004). The underlying mechanism of UDCA is unknown, but it may decrease bile acids like deoxycholic acid which may have carcinogenic potential.

\subsection{Aminosalicylates}

Aminosalicylates are used for maintenance therapy in many patients with UC for prolonged periods of time. Studies in England have shown a 75 to $90 \%$ reduction in the incidence of CRC (Eaden et al., 2000a). Both mesalazine and sufasalazine have chemoprotective effects with dose response effect. Mesalazine was somewhat superior and reduced cancer by $81 \%$ at doses > 1.2 grams daily (Moody et al., 1996; Rubin et al., 2006b; van Staa et al., 2005). Also, the longer the duration of mesalazine use, the more pronounced the effect (van Staa et al., 2005). Other studies have noted $60 \%$ to $72 \%$ risk reduction rates of CRC with the use of mesalamine. This benefit was separate from the risk reduction associated with surveillance colonoscopy (Rubin et al., 2006b; Velayos et al., 2006). Unfortunately, this benefit is lost with cessation of the drug as noted in a retrospective study with only $3 \%$ of patients on mesalamine developing CRC compared to $31 \%$ of patients who stopped or could not comply with treatment (Moody et al., 1996). Similar to the UDCA, there are some conflicting studies which did not achieve risk reductions of CRC with any statistical significance (Bernstein et al., 2003; Lindberg et al., 2001; Ullman et al., 2008). A large meta-analysis of the studies using mesalamine showed a preventative effect for CRC with mesalamine use (OR 0.51; 95\% CI, 0.37-0.69) and for CRC plus dysplasia (OR 0.51; 95\% CI, 0.38-0.69). However, mesalamine did not lower the overall risk of dysplasia (OR 1.18; 95\% CI, 0.41-3.43) (Velayos 
et al., 2005). Given this understanding of mesalamine being protective against CRC but not specifically for dysplasia, it is unclear when mesalamine treatment provides the greatest chemopreventive benefits in the dysplasia-carcinoma sequence. In one retrospective study of high and low dose mesalamine in patients with no dysplasia, indefinite dysplasia, and low grade dysplasia, the largest benefit was found in patients taking high dose mesalamine (>2grams per day) and no dysplasia or indefinite for dysplasia (Ullman et al., 2008). Based on this study it is hypothesized that the most benefit is found early on in the dysplasiacarcinoma sequence prior to any significant dysplastic changes. The underlying mechanism of action of the anti-neoplastic effects has been postulated to be its potential antiinflammatory activity, promotion of apoptosis of CRC tissue with no effect on normal mucosa, or improved DNA replication fidelity in CRC cells.

\subsection{Corticosteroids and Nonsteroidal anti-inflammatory drugs (NSAID)}

Continuing with the anti-inflammatory hypothesis to reduce CRC risk, corticosteroids have been evaluated given their known anti-inflammatory effects. While not the primary endpoint, most studies have found no chemoprotective effect with the use of corticosteroids. However, some studies found a $60 \%$ risk reduction with the use of oral prednisone for greater than one year (OR 0.4; 95\% CI 0.2 to 0.8) (Velayos et al., 2006). However, regardless of the potential treatment benefit, the toxicity associated with chronic steroid use limits the benefits of this potential treatment. While NSAID use has been show to be chemoprotective in sporadic CRC, its use in UC related CRC is less clear. A recent study of patients with a history of IBD and NSAID use did not achieve statistical significance (OR 0.47; 95\% CI, 0.121.86). The results, however, were suggestive of a potential risk reduction, but no definitive recommendations can be made (Samadder et al., 2011).

\subsection{Immunomodulators and biologic agents}

Since immunomodulators are the cornerstone of therapy for many patients with UC, their potential risk reduction benefits have been evaluated. In patients who were free of dysplasia neither 6-mercaptopurine (6-MP) nor azathioprine (AZA) showed any protection on progression to CRC after eight years (Matula et al., 2005). Among patients with extensive colitis and prolonged use of AZA, there was still no reduced cancer risk (Connell et al., 1994). Even in high risk patients with associated PSC, use of AZA did not provide any chemopreventive benefits (Tung et al., 2001). Similarly, 6-MP did not find any CRC risk reduction, but importantly, it also did not show any increased risk of cancer in the setting of prolonged use (Korelitz et al., 1999). Given the lack of evidence supporting CRC risk reduction with immunomodulators, they cannot be recommended as chemoprophylaxis.

\subsection{Supplements (folic acid, calcium, and multivitamins)}

In sporadic CRC, folic acid deficiency has been associated with spontaneous CRC formation (Freudenheim et al., 1991). Patients with UC are predisposed to folate deficiency from both poor nutritional intake and intestinal losses associated with inflammation in active disease. Despite this, current studies encorporating folic acid supplementation have been suggestive of a potential benefit but did not achieve any statistically significant reduction (Lashner et al., 1989; Lashner et al., 1996). However, the potential benefit may be confounded due to many patients already taking multivitamins or eating bread that is fortified with folic acid. 
Additionally, supplementing with calcium or multivitamins has also not been shown to reduce overall cancer risk in UC (Farraye et al., 2010).

\subsection{Statins}

More recently, statin therapy has been evaluated as a possible chemopreventive agent. In a case control study based in Israel of a colorectal cancer registry, patients on long term statin use had a reduced risk of developing CRC. In this study, patients with IBD had an overall 1.9 fold increased risk of developing CRC. This was attenuated though with long term statin use (OR 0.07; 95\% CI 0.01-0.78) (Samadder et al., 2011). Statin use for five years was found to have a large risk reduction of $94 \%$ in patients with IBD (Poynter et al., 2005).

\begin{tabular}{|l|l|}
\hline Agents & Chemoprotective benefit \\
\hline Aminosalicylates & Likely chemoprotective \\
& Chemoprotective with comorbid PSC \\
Statins & Potentially chemoprotective with UC alone \\
Corticosteroids & Potentially chemoprotective \\
NSAID & Toxicity outweights any benefit \\
Immunomodulators & Unclear \\
Folic acid & No effect \\
Calcium & Unclear \\
Multivitamin & No effect \\
\hline
\end{tabular}

Table 10. Chemoprotective effects of different agents

\section{Conclusion}

Patients with UC are at increased risk of CRC relative to the general population. The overall risk is still unclear and ranges from a mild to significantly increased risk relative to the general population. Specific patient risk factors including extent of disease, duration of disease, severity of inflammation, age of onset, family history, and associated PSC all increase the risk of CRC. With this increased risk, UC related cancer screening is recommended. More specific recommendations are still needed to help analyze the individual UC patient's risk profile when determining appropriate screening intervals. Additionally, both gastroenterologists and pathologist need continued training on current guidelines and definitions for dysplasia. With improved adherence to guidelines, and correct interpretation of dysplasia, more appropriate treatment can be initiated. The ultimate goal in UC patients is to lower their risk for CRC to that of the general population.

\section{References}

Ahmadi, A., Polyak, S., \& Draganov, P. Colorectal cancer surveillance in inflammatory bowel disease: The search continues. World Journal of Gastroenterology. Vol.15, No.1, January 2009, pp. 61-66 
Arber, N., \& Levin, B. Chemoprevention of colorectal neoplasia: the potential for personalized medicine. Gastroenterology. Vol.134, No.4, (April 2008), pp. 1224-37

Askling, J., Dickman, P., Karlén, P., Broström, O., Lapidus, A., Löfberg, R., \& Ekbom, A. Family history as a risk factor for colorectal cancer in inflammatory bowel disease. Gastroenterology. Vol.120, No.6, (May, 2001) pp. 1356-62

Aust, De., Terdiman, JP., Willenbucher, RF., Chang, CG., Molinaro-Clark, A., Baretton, GB., Loehrs, U., \&Waldman, FM. The APC/beta-catenin pathway in ulcerative colitisrelated colorectal carcinomas: a mutational analysis. Cancer. Vol.94, No.5, (March, 2002), pp. 1421-27

Axon, AT. Cancer surveillance in ulcerative colitis-a time for reappraisal. Gut. Vol.35, No.5, (May 1994), pp. 587-589

Baars, J., Looman, C., Steyerberg, E., Beukers, R., Tan, A., Weusten, B., Kuipers, E., van der Woude, C., The risk of inflammatory bowel disease-related colorectal carcinoma is limited: results from a nationwide nested case-control study. American Journal of Gastroenterology. Vol.106, No.2, (February 2011), pp. 319-28

Beeker, C., Kraft, JM., Souhwell, BG., \& Jorgensen, CM., Colorectal cancer screening in older men and women: qualitative research findings and implications for intervention. Journal of Community Health. Vol.25, No.3, (June 2000), pp. 263-78

Befrits, R., Ljung, T., Jaramillo, E., \& Rubio, C. Low-grade dysplasia in extensive, longstanding inflammatory bowel disease: a follow-up study. Diseases of Colon $\mathcal{E}$ Rectum. Vol.45, No.5, (May 2007), pp. 574-83

Bernstein, CN., Blanchard, JF, Metge, C., \& Yogendran, M. Does the use of 5aminosalicylates in inflammatory bowel disease prevent the development of colorectal cancer. American Journal of Gastroenterology. Vol.98, No.12, (December 2003), pp. 2784-88

Bernstein, CN., Shanahan, F. \& Weinstein, WM. Are we telling patients the truth about surveillance colonoscopy in ulcerative colitis. Lancet. Vol.343, No.8889, (January 1994), pp. 71-4

Bernstein, CN., Weinstein, WM ., Levine, DS., \& Shanahan, F. Physicians perceptions of dysplasia and approaches to surveillance colonoscopy in ulcerative colitis. Vol.90, No.12, (December 1995), pp. 2106-14

Blackstone, MO., Riddell, RH., Rogers, BH., \& Levin, B. Dysplasia-associated lesion or mass (DALM) detected by colonoscopy in long-standing ulcerative colitis: an indication for colectomy. Gastroenterology. Vol.80, No.2, (February 1981) pp. 366-74

Brackmann, S., Anderson, SN., Aamodt, G., Roald, B., Langmark, F., Clausen, OP., Aadland, E., Fausa, O., Rydning, A., \& Vatn, MH. Two distinct groups of colorectal cancer in inflammatory bowel disease. Inflammatory Bowel Diseases. Vol.15, No.1, (January 2009), pp. 9-16

Brentnall, TA., Crispin, DA., Rabinovitch, PS., Haggitt, RC., Rubin, CE., Stevens, AC., \& Burmer, GC. Mutations in the p53 gene: an early marker of neoplastic progression in ulcerative colitis. Gastroenterology. Vol. 107, No.2, (August 1994), pp. $369-78$

Broomé, U., Löfberg, R., Beress, B., \& Eriksson, L. Primary sclerosing cholangitis and ulcerative colitis: evidence for increased neoplastic potential. Hepatology. Vol.22, No.5, (November 1995), pp. 1404-8

Burner, GC., Rabinovitch, PS., Haggitt, RC., Crispin, DA., Brentnall, TA., Kolli, VR., Stevens, AC., \& Rubin, CE. Neopplastic progression in ulcerative colitis: histology, DNA 
content, and loss of a p53 allele. Gastroenterology. Vol.103, No.5 , (November 1992), pp. 1602-10

Cairns, S., Scholefield, J., Steele, R., Dunlop, M., Thomas, H., Evans, G., Eaden, J., Rutter, M., Atkin, W., Saunders, B., Lucassen, A., Jenkins, P., Fairclough, P., \& Woodhouse, C. Guidelines for colorectal cancer screening and surveillance in moderate and high risk groups (update from 2002). Gut. Vol.59, No.5, (May 2010), pp. 666-89

Choi, PM. Predominance of rectosigmoid neoplasia in ulcerative colitis and its implication on cancer surveillance. Gastroenterology. Vol.104, No.2, (February 1993), pp. 666-67

Collins, R., Feldman, M., \& Fordtran, J. Colon cancer dysplasia and surveillance in patients with ulcerative colitis. New England Journal of Medicine. Vol.316, (June 1987), pp. 1654-58

Collins, R., Lennard-Jones, JE., Williams, CB., Talbot, IC., Price, AB., \& Wilkinson, KH. Factors affecting the outcome of endoscopic surveillance for cancer in ulcerative colitis. Gastroenterology. Vol.107, No.4, (1994), pp. 934-44

Connell, WR., Kramm, MA., Dickson, M., Balkwill, AM., Ritchie, JK., \& Lennard-Jones, JE. Long-term neoplasia of malignancy after azathioprine treatment in inflammatory bowel disease. Lancet. Vol.343, No.8908, (May 1994), pp.1249-52

Crohn, B., Rosenberg, H., The sigmoidoscopic picture of chronic ulcerative colitis (nonspecific). American Journal of Medical Science. Vol.170. (1925), pp. 220-7

Dekker, E., van den Broek, FJ., Reitsma, JB., Hardwick, JC., Offerhaus, GJ., van Deventer, SJ., Hommes, DW., \& Fockens, P. Narrow-band imaging compared with conventional colonoscopy for the detection of dysplasia in patients with longstanding ulcerative colitis. Endoscopy. Vol.39, No.3 (March 2007), pp. 216-21

Dixon, MF., Brown., LJ., Gilmour, HM., Price, AB., Smeeton, NC., Talbot, IC., \& Williams, GT. Observer variation in the assessment of dysplasia in ulcerative colitis. Histopathology. Vol.13, No.4, (October 1988), pp.385-397

Dorer, R., \& Odze, RD. AMACR immunostaining is useful in detecting dysplastic epithelium in Barrett's esophagus, ulcerative colitis, and Crohn's disease. American Journal of Pathology. Vol.30, No.7, (July 2006) pp. 871-77

Eaden, J., \& Mayberry, J. Colorectal cancer complicating ulcerative colitis: a review. The American Journal of Gastroenterology. Vol.95, No.10, (October 2000), pp. 2710-2719

Eaden, J., \& Mayberry, JF. Guidelines for screening and surveillance of asymptomatic colorectal cancer in patients with inflammatory bowel disease. Gut. Vol.51, (October 2002) pp. Supplement 5:V10-2

Eaden, J., Abrams, K, McKay, H. Denley, H. \& Mayberry, J. Inter-observer variation between general and specialist gastrointestinal pathologists when grading dysplasia in ulcerative colitis. Journal of pathology. Vol.194, No.2, (June 2001), pp. 152-57

Eaden, J., Abrams, KR., \& Mayberry, JF. The risk of colorectal cancer in ulcerative colitis: a meta-analysis. Gut. Vol.48, No.4, (April 2001), pp. 526-35

Eaden, J., Abrams, KR., Ekbom, A., Jackson, E., \& Mayberry, JF. Colorectal cancer prevention in ulcerative colitis: a case-control study. Alimentary Pharmacology $\mathcal{E}$ Therapeutics. Vol.14, No.2, (February 2000), pp. 145-53

Eaden, J., Ward, BA., \& Mayberry, JF. How gastroenterologists screen for colon cancer in ulcerative colitis: an analysis of performance. Gastrointestinal Endoscopy. Vol.51, No.2, (February 2000), pp. 123-128 
Ekbom, A., Helmick, C., Zack, M., \& Adami HO. Ulcerative colitis and colorectal cancer. A population-based study. New England Journal of Medicine. Vol.323, No.18, (November 1990), pp. 1228-33

Engelsgjerd, M., Farraye, FA., \& Odze, RD. Polypectomy may be adequate treatment for adenoma-like dysplastic lesions in chronic ulcerative colitis. Gastroenterology. Vol.117, No.6, (December 1999) pp. 1288-94; discussion 1488-91

Farraye, FA., Odze, R., Eaden, J., \& Itzkowitz, S. AGA technical review on the diagnosis and management of colorectal neoplasia in inflammatory bowel disease. Gastroenterology, Vol.138, (February 2010), pp. 746-74

Fleisher, AJ.,Esteller, M., Harpaz, N., Leytin, A., Rashid, A., Xu, Y., Liang, J., Stine, OC., Yin, J., Zou, TT., Abraham, JM., Kong, D., Wilson, KT., James, SP., Herman, JG., \& Melzer, SJ. Microsatellite instability in inflammatory bowel disease-associated neoplastic lesions is associated with hypermethylation and diminished expression of the DNA mismatch repair gene, hMLH1. Cancer Research. Vol.60, No.17, (September 2000), pp. 4864-8

Freudenheim, JL., Graham, S. Marshal, JR. Haughey, BP., Cholewinski, S., \& Wilkinson, G. Folate intake and carcinogenesis of the colon and rectum. International Journal of Epidemiology. Vol, 20, No.2, (June 1991), pp. 368-74

Friedman, S., Odze, RD., \& Farraye, FA. Management of neoplastic polyps in inflammatory bowel disease. Inflammatory Bowel Diseases. Vol.9, No.4, (July 2003), pp.260-6

Geary, RB., Wakeman, CJ., Barclay, ML. Chapman, BA., Collett, JA., Burt, MJ., \& Frizelle, FA. Surveillance for dysplasia in patients with inflammatory bowel disease: a national survey of colonoscopic practice in New Zealand. Diseases of Colon $\mathcal{E}$ Rectum. Vol.47, No.3, (March 2004), pp. 314-22

Goldman, H. Significance and detection of dysplasia in chronic colitis. Cancer. Vol.78, No.11, (December 1996), pp. 2261-63

Gorfine, S., Bauer, J., Harris, M., \& Kreel, I. Dysplasia complicating chronic ulcerative colitis: is immediate colectomy warranted. Diseases of Colon $\mathcal{E}$ Rectum. Vol.43, No.11, (November 2000), pp. 1575-81

Greenstein, AJ. Sachar, DB., Smith, H., Pucillo, A., Papatestas, AE., Kreel, I., Geller, SA., Janowitz, HD., \& Aufses, AH. Cancer in universal and left-sided ulcerative colitis: factors determining risk. Gastroenterology. Vol.77, No.2, (August 1979), pp. 290-94

Guindi, M., \& Riddell, R. The pathology of epithelial pre-malignancy of the gastrointestinal tract. Best Practice E Research Clinical Gastroenterology. Vol.15, No.2, (April 2001), pp. 191-210

Gumaste, V., Sachar, DB., \& Greenstein, AJ. Benign and malignant colorectal strictures in ulcerative colitis. Gut. Vol.33, No.7, (July 1992), pp. 938-41

Gupta, R., Harpaz, N., Itzkowitz, S., Hossain, S., Matula, S., Kornbluth, A., Bodian, C., \& Ullman, T. Histologic inflammation is a risk factor for progression to colorectal neoplasia in ulcerative colitis: a cohort study. Gastroenterology. Vol.133, No.4, (October 2007), pp.1099-1341

Gyde, SN. Screening for colorectal cancer in ulcerative colitis: dubious benefits and high costs. Gut. Vol.31, No.10, (October 1990), pp. 1089-92

Gyde, SN., Prior, P., Allan, RN., Stevens, A., Jewell, DP., Truelove, SC., Löfberg, R., Brostrom, O., \& Hellers, G. Colorectal cancer in ulcerative colitis: a cohort study of primary referrals from three centres. Gut. Vol.29, No.2, (February 1988), pp. 206-17 
Haskall, H. Andrews, CW., Reddy, SI., Dendrinos, K., Farraye, FA., Stucchi, AF., Becker, JM., \& Odze, RD. Pathologic features and clinical significance of "backwash" ileitis in ulcerative colitis. American Journal of Surgical Pathology. Vol.29, No.11, (November 2005), pp. 1472-81

Hata, K., Watanabe, T., Kazama, S., Suzuki, K., Shinozaki, M., Yokoyama, T., Matsuda, K., Muto, T., \& Nagawa, H. Earlier surveillance colonscopy programme improves survival in patients with ulcerative colitis associated colorectal cancer: results of a 23-year surveillance programme in Japanese population. British Journal of Cancer. Vol.89, No.7, (October 2003), pp. 1232-1236

Hsieh, CJ., Klump, B., Holzmann, K., Borchard, F., Gregor, M., \& Porschen, R. Hypermethylation of the p16ink4a promoter in colectomy specimens of patients with long-standing and extensive ulcerative colitis. Cancer Research. Vol.58, No.17, (September 1998), pp. 3942-5

Hurlstone, DP., Sanders, DS., Lobo, AJ., McAlindon, ME., \& Cross, SS. Indigo carmineassisted high-magnification chromoscopic colonoscopy for the detection and characterization of intraepithelial neoplasia in ulcerative colitis: a prospective evaluation. Endoscopy. Vol.37, No.12, (December 2005), pp. 1186-92

Hussain, SP., Amstad, P., Raja, K., Ambs, S., Nagashima, M., Bennett, WP., Shields, PG., Ham, AJ., Swenberg, JA., Marrogi, AJ., \& Harris, CC. Increased p53 mutation load in noncancerous colon tissue from ulcerative colitis: a cancer-prone chronic inflammatory disease. Cancer Research. Vol.60, No.13 (July, 2000), pp. 3333-37

Ilyas, T., \& Talbot, IC. p53 expression in ulcerative colitis: a longitudinal study. Gut. Vol.37. No.6, (December 1995), pp. 802-4

Issa, JP., Ahuja, N., Toyota, M., Bronner, MP., \& Brentnall TA. Accelerated age-related CpG island methylation in ulcerative colitis. Cancer Research. Vol.61, No.9, (May 2001), pp. 3573-7

Itzkowitz, S. Colon carcinogenesis in inflammatory bowel disease: applying molecular genetics to clinical practice. Journal Clinical Gastroenterology. Vol.36, (May-June 2003) pp. s70-s74

Itzkowitz, S., \& Harpaz, N., Diagnosis and management of dysplasia in patients with inflammatory bowel diseases. Gastroenterology. Vol.126, No.6, (May 2004), pp. 163448

Itzkowitz, S., \& Present, DH. Consensus conference: colorectal cancer screening and surveillance in inflammatory bowel disease. Inflammatory Bowel Diseases. Vol.11, No.3, (March 2005), pp. 314-21

Itzkowitz, S., \& Ullman T. The world isn't flat. Gastrointestinal Endoscopy. Vol.60, No.3, (September 2004), pp. 426-27

Itzkowitz, S., \& Yio, X. Inflammation and cancer IV. colorectal cancer in inflammatory bowel disease: the role of inflammation. American Journal of Physiology Gastrointestinal Liver Physiology. Vol.287, (July 2004), pp. G7-G17

Jess, T., Loftus, E., Velayos, F., Harmsen, S., Zinsmeister, A., Smyrk, T., Schleck, C., Tremaine, W., Melton, LJ., Munkholm, P., \& Sandborn, W. Risk of intestinal cancer in inflammatory bowel disease: a population-based study from Olmsted county, Minnesota. Gastroenterology. Vol.130, No.4, (April 2006), pp. 1039-46 
Karlén, P., Kornfeld, D., Broström, O., Löfberg, R., Persson, P-G., \& Ekbom, A. Is colonoscopic surveillance reducing colorectal cancer mortality in ulcerative colitis? A population based case control study. Gut. Vol.42, No.5, (May 1998), pp. 711-4

Karlén, P., Young, E., Broström, O., Löfberg, R., Tribukait, B., Ost, K., Bodian, C., \& Itzkowitz, S. Sialyl-Tn antigen as a marker of colon cancer risk I nulcerative colitis: relation to dysplasia and DNA aneuploidy. Gastroenterology. Vol.115, No.6, (December 1998), pp. 1395-404

Katzka, I., Brody, RS., Morris, E., \& Katz, S. Assessment of colorectal cancer risk in patients with ulcerative colitis: experience from a private practice. Gastroenterology. Vol.85, No.1, (July 1983), pp. 22-9

Kiesslich, R., \& Neurath, MF. What new endoscopic imaging modalities will become important in the diagnosis of IBD. Inflammatory Bowel Diseases. Vol.14, No.S2, (October 2008), pp. Supplement 2:S172-6

Kiesslich, R., Fritsch, J., Holtmann, M., Koehler, H., Stolte, M., Kanzler, S., Nafe, B., Jung, M., Galle, PR., \& Neurath, MF. Chromoscopy-guided endomicroscopy increases the diagnostic yield of intraepithelial neoplasia in ulcerative colitis. Vol.132, No.3, (March 2007), pp. 874-82

Kiesslich, R., Fritsch, J., Holtmann, M., Koehler, H., Stolte, M., Kanzler, S., Nafe, B., Jung, M., Galle, PR., \& Neurath, MF. Methylene blue-aided chromoendoscopy for the detection of intraepithelial neoplasia and colon cancer in ulcerative colitis. Gastroenterology.Vol.123, No.4, (April 2003), pp.880-8

Koobatian, GJ. \& Choi, PM. Safety of surveillance colonoscopy in long-standing ulcerative colitis. American Journal of Gastroenterology. Vol.89, No.9, (September 1994), pp. $1472-5$

Korelitz, BI., Mirsky, FJ., Fleisher, MR., Warman, JI., Wisch, N., \& Gleim, GW. Malignant neoplasms subsequent to treatment of inflammatory bowel disease with 6mercaptopurine. American Journal of Gastroenterology. Vol.94, No.11, (November 1999), pp. 3248-53

Kottachichi, D., Yung, D., \& Marshall, J. Adherence to guidelines for surveillance colonoscopy in patients with ulcerative colitis at a Canadian quaternary care hospital. Canadian Journal of Gastroenterology. Vol.23, No.9, (September 2009), pp. 613-17).

Kudo, S., Rubio, CA., Teizeira, CR., Kashida, H., \& Kogure, E. Pit pattern in colorectal neoplasia: endoscopic magnifying view. Endoscopy. Vol.33, No.4, (April 2003), pp. 367-73

Lakatos, PL., \& Lakatos, L. Risk for colorectal cancer in ulcerative colitis: changes, causes and management strategies. World Journal of Gastroenterology. Vol.14, No.25, (July 2008), pp. 3937-47

Langholz, E., Munkholm, P., Davidsen, M., \& Binder, V. colorectal cancer risk andmortality in patients with ulcerative colitis. Gastroenterology. Vol.103, No.5, (November 1992), pp. $1444-51$

Lashner, B., Provencher, KS., Seidner, DL., Knesebeck, A., \& Brzezinski, A.The effect of folic acid supplementation on the risk for cancer or dysplasia in ulcerative colitis. Gastroenterology. Vol.112. No.1, (January 1997), pp. 29-32 
Lashner, B., Shapiro, B., Husain, A., \& Goldblum, J. Evaluation of the usefulness of testing for p53 mutations in colorectal cancer surveillance for ulcerative colitis. American Journal of Gastroenterology. Vol.94, No.2, (February 1999), pp. 456-462

Lashner, B., Turner, B., Bostwick, D., Frank, P., \& Hanauer, S. Dysplasia and cancer complicating strictures in ulcerative colitis. Digestive Diseases and Sciences. Vol.35, No.3, (March 1990), pp. 349-52

Lennard-Jones, JE., Melville, DM., Morson, BC., Ritchie, JK. \& Williams, CB. Precancer and cancer in extensive ccolitis: findings among 401 patients over 22 years. Gut. Vol.31, No.7, (July 1990), pp. 800-6

Lim, Ch., Dixon, MF., Vail, A., Forman, D., Lynch, DA., \& Axon, AT. Ten year follow up of ulcerative colitis patients with and without low grade dysplasia. Gut. Vol.52, No.8, (August 2003), pp. 1127-32

Lindberg, B., Broome, U., \& Persson, B., Proximal colorectal dysplasia or cancer in ulcerative colitis. The impact of primary sclerosing cholangitis and sulfasalazine: results from a 20-year surveillance study. Diseases of Colon \& Rectum. Vol.44, No.1, (January 2001), pp. 77-85

Lindberg, B., Persson, B., Veress, B., Ingelman-Sundberg, H., \& Granqvist, S. Twenty years' colonoscopic surveillance of patients with ulcerative colitis. Scandinavian Journal of Gastroenterology. Vol.31, No.12, (December 1996), pp.1195-1205

Lipkus, IM., Rimer, BK., Lyna, PR>, Pradhan, AA., Conaway, M., \& Woods-Powell, CT. Colorectal screening patterns and perceptions of risk among African-American users of a community health center. Journal of Community Health. Vol.21, No.6, (December 1996), pp. 409-27

Löfberg, R., Broström, O., Karlén, P., Tribukait B, \& Ost, A. Colonoscopic surveillance in long-standing total ulcerative colitis-a 15 year follow-up study. Gastroenterology. Vol.99, No.4, (October 1990), pp. 1021-31

Loftus, E., Aguilar, H., Sandborn, W., Tremaine, W., Krom, R., Zinsmeister, A., Graziadei, I., \& Wiesner, R. Risk of colorectal neoplasia in patients with primary sclerosing cholangitis and ulcerative colitis following orthotopic liver transplantation. Hepatology. Vol. 27, No.3, (March 1998), pp. 685-690

Loftus, E., Aguilar, H., Sandborn, W., Tremaine, W., Mahoney, DW., Zinsmeister, AR., Offord, KP., \& Melton, LJ Risk of colorectal neoplasia in patients with primary sclerosing cholangitis. Gastroenterology. Vol.110, No.2, (1996) pp. 432-40

Marion, JF., Waye, JD., Present, DH., Israsel, Y., Bodian, C., Harpaz, N., Chapman, M., Itzkowtiz, S., Steinlauf, AF., Abreu, MT., Ullman, TA., Aisenber, J., \& Mayer, L. Chromoendoscopy-targeted biopsies are superior to standard colonoscopic surveillance for detecting dysplasia in inflammatory bowel disease patients: a prospective endoscopic trial. American Journal of Gastroenterology. Vol.103, No.9, (September 2008), pp. 2342-9

Mathy, C., Schneider, K., Chen, YY., Varma, M., Terdiman, JP., \& Mahadevan, U. Gross versus microscopic pancolitis and the occurrence of neoplasia in ulcerative colitis. Inflammatory Bowel Diseases. Vol.9, No.6, (November 2003), pp. 351-5

Matsumoto, T., Nakamura, S., Jo, Y., Yao, T. \& Lida, M. Chromoscopy might improve diagnostic accuracy in cancer surveillance for ulcerative colitis. American Journal of Gastroenterology. Vol.98, No.8, (August 2003), pp. 1827-33 
Matula, S., Croog, V., Itzkowtiz, S., Harpaz, N., Bodian, C., Hossain, S., \& Ullman, T. Chemoprevention of colorectal neoplasia in ulcerative colitis: the effect of 6mercaptopurine. Clinical Gastroenterology \& Hepatology. Vol.3, No.10, (October 2005), pp. 1015-21

Melville, DM., Jass, JR., Morson, BC., Pollock, DJ, Richman, PI, Shepherd, NA., Ritchie, JK., Love, SB., \& Lennard-Jones, JE. Observer study of the grading of dysplasia in ulcerative colitis: comparison with clinical outcome. Human Pathology. Vol.20, No.10, (October 1989) pp. 1008-14

Moody, GA., Jayanthi, V., Probert, CS., Mac Kay, H., \& Mayberry, JF. Long-term therapy with suphasalazine protects against colorectal cancer in ulcerative colitis: a restrospective study of colorectal cancer risk and compliance with treatment in Leicestershire. European Journal of Gastroenterology \& Hepatology. Vol.8, No.12, (December 1996), pp. 1179-83

Mpofu, C., Watson, AJ., \& Rhodes, JM. Strategies for detecting colon cancer and/or dysplasia in patients with inflammatory bowel disease (Review). The Cochrane Database of Systemic Reviews. Vol.2, (2004), pp. 1-14

Munkholm, P. Review article: the incidence and prevalence of colorectal cancer in inflammatory bowel disease. Alimentary Pharmacology \& Therapeutics. Vol.18, (September 2003), pp. Supplement 2:1-5

Nguyen, GC., Frick, KD., \& Dassopoulos, T. Medical decision analysis for the management of unifocal, flat, low-grade dysplasia in ulcerative colitis. Gastrointestinal Endoscopy. Vol.69, No.7, (June 2009), pp. 1299-1310

Nuako, KW, Ahlquist, DA., Sandborn, WJ., Mahoney, DW., Siems, DM., \& Zinsmeister, AR. Primary sclerosing cholangitis and colorectal carcinoma in patients with chronic ulcerative colitis: a case control study. Cancer. Vol.82, No.5, (March 1998) pp. 822-26

Nuako, KW., Ahlquist, DA., Mahoney, DW., Schaid, DJ., Siems, DM., \& Lindor, NM. Familial predisposition for colorectal cancer in chronic ulcerative colitis: a case control-study. Gastroenterology. Vol.115, No.5, (November 1998), pp.1079-83

Nugent, FW., Haggit, RC., \& Gilpin, PA. Cancer surveillance in ulcerative colitis. Gastroenterology. Vol.100, No.5, (May 2002), pp. 615-20

Obrador, A., Ginard, D., \& Barranco, L. Review article: colorectal cancer surveillance in ulcerative colitis - what should we be doing. Alimentary Pharmacology $\mathcal{E}$ Therapeutics. Vol.24, (October 2006), pp. Supplement 3:56-63

Odze, RD. Adenomas and adenoma-like DALMs in chronic ulcerative colitis: a clinical, pathological, and molecular review. American Journal of Gastroenterology. Vol.94, No.7, (July 1999), pp. 1746-50

Odze, RD. What are the guidelines for treating adenoma-like DALMs in UC. Inflamatory Bowel Diseases. Vol.14., (October 2008), pp. Suppl 2: S243-4

Odze, RD., Farraye, FA., Hecht, JL., \& Hornick, JL. Long-term follow-up after polypectomy treatment for adenoma-like dysplastic lesions in ulcerative colitis. Clinical Gastroenterology \& Hepatology. Vol.2, No.7, (July 2004), pp. 534-41

Odze, RD., Goldblum, J., Noffsinger, A., Alsaigh, N., Rybicki, LA., \& Fogt, F. Interobserver variability in the diagnosis of ulcerative colitis-associated dysplasia by telepathology. Modern Pathology. Vol.15, No.4, (April 2002), pp. 379-86 
Pandi, DS., Loftus, EV., Kremers, WK., Keach, J., \& Lindor, KD. Ursodeoxycholic acid as a chemopreventive agent in patients with ulcerative colitis and primary sclerosing cholangitis. Gastroenterology. Vol.125, No.4, (April 2003), pp. 889-93

Pinczowski, D., Ekbom, A., Baron, J., Yuen, J., \& Adami, HO. Risk factors for colorectal cancer in patients with ulcerative colitis: a case-control study. Gastroenterology. Vol.107, No.1, (July 1994), pp. 117-20

Poynter, JN., Gruber, SB., Higgins, PD., Almog, R., Bonner, JD., Rennert, HS., Low, M., Greenson, JK., \& Rennert, G. Statins and risk of colorectal cancer. New England Journal of Medicine. Vol.352, No.21, (May 2005), pp. 2184-92

Price, JH. Perceptions of colorectal cancer in socioeconomically disadvantaged population. Journal Community Health. Vol.18, No.6, (December 1993), pp. 347-62

Provenzale, D., Kowdley, KV., Arora, S., \& Wong, JB. Prophylactic colectomy or surveillance for chornic ulcerative colitis? A decision analysis. Gastroenterology. Vol.109, No.4, (October 1995), pp. 188-96

Ransohoff, DF. Colon cancer in ulcerative colitis. Gastroenterology. Vol.94, No.4, (April 1988), pp. 1089-91

Reddy, SI., Friedman, S., Telford, J., Strate, L., Ookubo, R., \& Banks, P. Are patients with inflammatory bowel disease receiving optimal care. American Journal of Gastroenterology. Vol.100, No.6, (June 2005), pp. 1357-61

Riddell, RH., Goldman, H., Ransohoff, DF., Appelman, HD., Fenoglio, CM., Haggitt, RC., Ahren, C., Correa, P., Hamilton, SR., Morson, BC., \& et al. Dysplasia in inflammatory bowel disease: standardized classification with provisional clinical applications. Human Pathology. Vol.14, No.11, (November 1983), pp. 931-68

Rubin, CE., Haggitt, RC., Burmer, GC., Brentnall, TA., Stevens, AC., Levine, DS., Dean, PJ., Kimmey, M., Perera, DR., \& Rabinovitch, PS. DNA aneuploidy in colonic biopsies predicts future development of dysplasia in ulcerative colitis. Gastroenterology. Vol.103, No.5, (November 1992), pp. 1611-20

Rubin, DT., Huo D., Rothe, J., Hetzel, JT., Sedrak, M., Yadron, N., Bunnag, A., Hart, J., \& Turner, JR. Increased inflammatory activity is an independent risk factor for dysplasia and colorectal cancer in ulcerative colitis: a case-control analysis with blinded prospective reviews of pathology. Gastroenterology. Vol.130, (2006), pp. Supplement A2

Rubin, DT., LoSavio, A., Yadron, N., Huo, D., \& Hanauer, SB. Aminosalicylate therapy in the prevention of dysplasia and colorectal cancer in ulcerative colitis. Clinical Gastroenterology \& Hepatology. Vol.4, No.11, (November 2006), pp.1346-50

Rubin, PH., Friedman, S., Harpaz, N., Goldstein, E., Weiser, J., Schiller, J., Wayne, JD., Present, DH. Colonoscopic polypectomy in chronic colitis: conservative management after endoscopic resection of dysplastic polyps. Gastroenterology. Vol.117, No.6, (1999), pp. 1295-1300

Rutter, M. A practical guide and review of colonoscopic surveillance and chromoendoscopy in patients with colitis. Frontline Gastroenterology. Vol.1, (July 2010), pp.126-129

Rutter, M., Saunders, B., Wilkinson, K., Rumbles, S., Schofield, G., Kamm, M., Williams, C., \& Forbes, A. Most dysplasia in ulcerative colitis is visible at colonoscopy. Gastrointestinal Endoscopy. Vol.60, No.3, (September 2004), pp. 334-9

Rutter, M., Saunders, B., Wilkinson, K., Rumbles, S., Schofield, G., Kamm, M., Williams, C., Price, A., Talbot, I., \& Forbes, A. Cancer surveillance in longstanding ulcerative 
colitis endoscopic appearances help predict cancer risk. Gut. Vol.53, No.12, (December 2004), pp. 1813-16

Rutter, M., Saunders, B., Wilkinson, K., Rumbles, S., Schofield, G., Kamm, M., Williams, C., Price, A., Talbot, I., \& Forbes, A. Severity of inflammation is a risk factor for colorectal neoplasia in ulcerative colitis. Gastroenterology. Vol.126, No.2, (February 2004), pp. 451-59

Rutter, M., Saunders, B., Wilkinson, K., Rumbles, S., Schofield, G., Kamm, M., Williams, C., Price, A., Talbot, I., \& Forbes, A. Thirty-year analysis of a colonoscopic surveillance program for neoplasia in ulcerative colitis. Gastroenterology. Vol.130, No.4, (April 2006), pp. 1030-8

Rutter, M., Saunders, BP., Schofield, G., Forbes, A., Price, AB., \& Talbot, IC. Pancolonic indigo carmine dye spraying for the detection of dysplasia in ulcerative colitis. Gut. Vol.53, No.2, (February 2004), pp. 256-60

Samadder, NJ., Mukherjee, B., Huang, SC., Ahn, J., Rennert, H., Greenson, J., Rennert, G., \& Gruber, S. Risk of colorectal cancer in self-reported inflammatory bowel disease and modification of risk by statin and NSAID use. Cancer. Vol.117, (April 2011), pp. $1640-8$

Sato, F., Harpaz, N., Shibata, D., Xu, Y., Yin, J., Mori, Y., Zou, TT., Wang, S., Desai, K., Leytin, A., Selaru, F., Abraham, JM., \& Melzer, S. Hypermethylation of p14ARF gene in ulcerative colitis-associated colorectal carcinogenesis. Cancer Research. Vol.62, No.4 , (February 2002), pp. 1148-51

Schlemper, RJ., Riddell, RH., Kato, Y., Borchard, F., Cooper, HS., Dwasey, SM., Dixon, MF., Fenoglio-Preiser, CM., Fléjou, JF., Geboes, K., Hattori, T., Hirota, T., Itabashi, M., Iwafuchi, M., Iwashita, A., Kim, YI., Kirchner, T., Klimpfinger, M., Koike, M., Lauwers, GY., Lewin, KJ., Oberhuber, G., Offner, F., Price, AB., Rubio, CA., Shimizu, M., Shimoda, T., Sipponen, P., Solcia, E., Stolte, M., Watanabe, H., \&Yamabe, H. The Vienna classification of gastrointestinal epithelial neoplasia. Gut. Vol.47, No.2, (August 2000), pp. 251-55

Sharan, R., \& Schoen, RE. Cancer in inflammatory bowel disease. An evidence-based analysis and guide for physicians and patients. Gastrointestinal Clinics of North America. Vol.31, No.1, (March 2002), pp. 237-54

Shetty, K., Rybicki, L., Brezinksi, A., Carey, WD., \& Lashner, BA. The risk for cancer or dysplasia in ulcerative colitis patients with primary sclerosing cholangitis. American Journal of Gastroenterology. Vol.94, No.6, (June 1999), pp. 1643-9

Sjoqvist, U., Tribukait., B. Ost, A., Einarsson, C., Oxelmark, \& Löfberg, R. Ursodeoxycholic acid treatment in IBD-patientes with colorectal dysplasia and/or DNA-anueploidy: a prospective, double-blind randomized controlled pilot study. Anticancer Research. Vol.24, No.5B, (September-October 2004), pp. 3121-27

Söderlund, S., Granath, F., Broström, O., Karlén, P., Löfberg, R., \& Askling, J. Inflammatory bowel disease confers a lower risk of colorectal cancer to females than to males. Gastroenterology. Vol.138, No.5, (May 2010), pp. 1697-703

Soetikno, R., Friedland, S., Kaltenbach, T., Chayama, K., Tanaka, S., Nonpolypoid (flat and depressed) colorectal neoplasm. Gastroenterology. Vol.130, No.2, (February 2006), pp. 566-76

Soetikno, R., Lin, O., Heidenreich, P., Young, H., \& Blackstone, M. Increased risk of colorectal neoplasia in patients with primary sclerosing cholangitis and ulcerative 
colitis: a meta-analysis. Gastrointestinal Endoscopy. Vol.56, No.1, (July 2002), pp. 4854

Sonnenberg, A., \& El-Serag, HB. Economic aspects of endoscopic screening for intestinal precancerous conditions. Gastroinestinal Endoscopy Clinics of North America. Vol.7, No.1, (January 1997), pp. 165-84

Tahara, T., Inoue, N., Hisamatsu, T., Kashiwagi, K., Takaishi, H., Kamai, T., Watanabe, M., Ishii, H., \& Hibi, T. Clinical significance of microsatellite instability in the inflamed mucosa for the prediction of colonic neoplasms in patients with ulcerative colitis. Journal of Gastroenterology E Hepatology. Vol.20, No.5, (May 2005), pp.710-15

Thomas, T., Abrams, KA., Robinson, RJ. \& Mayberry, JF. Meta-analysis: cancer risk of lowgrade dysplasia in chronic ulcerative colitis. Alimentary Pharmacology $\mathcal{E}$ Therapeutics. Vol.25, No.6, (March 2007), pp. 657-68

Torres, C., Antonioli, D., \& Odze RD. Polypoid dysplasia and adenomas in inflammatory bowel disease: a clinical, pathologic, and follow-up study of 89 polyps from 59 patients. American Journal of Surgical Pathology. Vol.22, No.3, (March 1988), pp. 27584

Tung, BY., Emond, MJ., Haggitt, RC., Bronner, MP., Kimmey, MB., Kowdley, KV., \& Brentnall, TA. Ursodiol use is associated with lower prevalence of colonic neoplasia in patients with ulcerative colitis and primary sclerosing cholangitis. Annals of Internal Medicine. Vol.134, No.2, (January 2001), pp. 89-95

Ullman, T, Loftus, EV., Kakar, S., Burgart, LJ., Sandborn, WJ. \& Tremaine, WJ. The fate of low grade dysplasia in ulcerative colitis. American Journal of Gastroenterology. Vol.97, No.4, (April 2002), pp. 922-27

Ullman, T., \& Itzkowitz, S. Intestinal inflammation and cancer. Gastroenterology. Vol.140, No.6, (May 2011), pp. 1807-16

Ullman, T., Croog, V., Harpaz, N., Hossain, S., Kornbluth, A., Bodian, C., \& Itzkowtiz, S. Progression to colorectal neoplasia in ulcerative colitis: effect of mesalamine. Clinical Gastroenterology \& Hepatology. Vol.6, No.11, (November 2008), pp. 1225-30

Umetani, N., Sasaki, S., Watanabe, T., Shinozaki, M., Matsuda, K., Ishigami, H., Ueda, E., \& Muto, T. Genetic alterations in ulcerative colitis-associated neoplasia focusing on APC, K-ras gene and microsatellite instability. Japanese Journal of Cancer Research. Vol.90, No.10, (October 1999), pp. 1081-7

van den Broek, FJ., Fockens, P., van Eeden, S., Reitsma, JB., Hardwick, JC., Stokkers, PC., \& Dekker, E. Endoscopic tri-modal imaging for surveillance in ulcerative colitis: randomized comparison of high-resolution endoscopy and autofluorescene imaging for neoplasia detection; and evaluation of narrow-band imaging for classification of lesions. Gut. Vol.57, No,8, (August 2008), pp. 1083-9

van Rijn, AF., Fockens, P., Siersema, P., \& Oldenburg, B. Adherence to surveillance guidelines for dysplasia and colorectal carcinoma in ulcerative and Crohns colitis patients in the Netherlands. World Journal of Gastroenterology. Vol.15, No.2, (January 2009), pp. 226-230

van Staa, TP., Card, T., Logan, RF., \& Leufkens, HG. 5-aminosalicylate therapy use and colorectal cancer risk in inflammatory bowel disease: a large epidemiological study. Gut. Vol.54, No.11, (November 2005), pp. 1573-78

Velayos, FS., Loftus, EV., Jess, T., Harmsen, WS., Bida, J., Zinsmeister, AR., Tremaine, WJ., \& Sandborn, WJ. Predictive and protective factors associated with colorectal cancer in 
ulcerative colitis: a case-control study. Gastroenterology. Vol.130, No.7, (June 2006), pp. 1941-49

Velayos, FS., Terdiman, JP., \& Walsh, JM. Effect of 5-aminosalicylate use on colorectal cancer and dysplasia risk: a systemic review and metaanalysis of observational studies. American Journal of Gastroenterology. Vol.100, No.6, (June 2005), pp. 1345-53

Vera, A., Gunson, BK., Ussatoff, V., Nightingal, P., Candinas, D., Radley, S., Mayer, AD., Buckels, JA., McMaster, P., Neuberger, J., \& Mirza, DF. Colorectal cancer in patients with inflammatory bowel disease after liver transplantation for primary sclerosing cholangitis. Transplantation. Vol.75, No.12, (June 2003), pp. 1983-88

Vernon, SW. Participation in colorectal cancer screening: a review. Journal of National Cancer Institute. Vol.89, No.19, (October 1997) pp. 1406-22

Vieth, M., Behrens, H., \& Stolte, M. Sporadic adenoma in ulcerative colitis: endoscopic resection is an adequate treatment. Gut. Vol.55, No.8, (August 2006), pp. 1151-55

Wilson, JM., Jungner, G. Principles and practice of screening for disease. World Health Organization Chronicles. Vol.22, No.11, (1968), pp. 1-163

Wolf, JM., Rybicki, LA, \& Lashner, BA. The impact of ursodeoxycholic acid on cancer, dysplasia and mortality in ulcerative colitis patients with primary sclerosing cholangitis. Alimentary Pharmacology \& Therapy. Vol.22, No.9, (November 2005), pp. 783-8

Woolrich, AJ., DaSilva, MD., \& Korelitz, BL. Surveillance in the routine management of ulcerative colitis: the predictive value of low-grade dysplasia. Gastroenterology. Vol.103, No.2, (August 1992), pp. 431-38

Yashiro, M., Carethers, JM., Laghi, L., Saito, K., Slezak, P., Jaramillo, E., Rbio, C., Koizumi, K., Hirakawa, K., \& Boland, CR. Genetic pathways in the evolution of morphologically distinct colorectal neoplasms. Cancer Research. Vol.61, No.6, (March 2001), pp. 2676-83. 


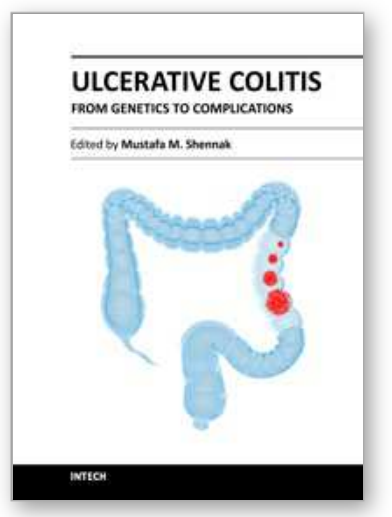

\author{
Ulcerative Colitis from Genetics to Complications \\ Edited by Prof. Mustafa Shennak
}

ISBN 978-953-307-853-3

Hard cover, 222 pages

Publisher InTech

Published online 18, January, 2012

Published in print edition January, 2012

Ulcerative Colitis (UC) is a rapidly evolving medical field, and will continue to be very exiting in the next few decades. Although the underlying cause of this disease is still unknown, results in research dealing with various issues related to this disease are published every day. Chapters included in this book review the most recent literature on related advancements in regard to this chronic disease, which is controllable but not curable. Aspects like epidemiology, pathophysiology, genetics, incriminated etiologies, clinical aspects, complications, and disease management, including advancements in the diagnostic and therapeutic options, were documented by well known clinicians, researchers, and world wide authorities in their fields. This book on UC will be a valuable addition to each doctor's library interested in this subject, or for physicians dealing with patients suffering from this disease. Authors have also included figures and diagrams to depict their point, and to easily reach the minds of the readers in the simplest way.

\title{
How to reference
}

In order to correctly reference this scholarly work, feel free to copy and paste the following:

Joseph D. Feuerstein and Sharmeel K. Wasan (2012). Colorectal Cancer in Ulcerative Colitis Patients, Ulcerative Colitis from Genetics to Complications, Prof. Mustafa Shennak (Ed.), ISBN: 978-953-307-853-3, InTech, Available from: http://www.intechopen.com/books/ulcerative-colitis-from-genetics-tocomplications/colorectal-cancer-in-ulcerative-colitis-patients

\section{INTECH}

open science | open minds

\section{InTech Europe}

University Campus STeP Ri

Slavka Krautzeka 83/A

51000 Rijeka, Croatia

Phone: +385 (51) 770447

Fax: +385 (51) 686166

www.intechopen.com

\section{InTech China}

Unit 405, Office Block, Hotel Equatorial Shanghai

No.65, Yan An Road (West), Shanghai, 200040, China

中国上海市延安西路65号上海国际贵都大饭店办公楼 405 单元

Phone: +86-21-62489820

Fax: $+86-21-62489821$ 
(C) 2012 The Author(s). Licensee IntechOpen. This is an open access article distributed under the terms of the Creative Commons Attribution 3.0 License, which permits unrestricted use, distribution, and reproduction in any medium, provided the original work is properly cited. 